\title{
Russian Gas Imports in Europe: How Does Gazprom Reliability Change the Game?
}

\author{
Joris Morbee* Stef Proost ${ }^{\dagger \ddagger}$ \\ CES Discussion Paper, July 15th, 2009
}

Europe's dependence on Russian gas imports has been the subject of increasing political concern after gas conflicts between Russia and Ukraine in 2006 and 2009. This paper assesses the potential impact of Russian unreliability on the European gas market, and how it affects European gas import strategy. We also study to what extent Europe should invest in strategic gas storage capacity to mitigate the effects of possible Russian unreliability. The European gas import market is described by differentiated competition between Russia and a-more reliable - competitive fringe of other exporters. The results show that Russian contract volumes and prices decline significantly as a function of unreliability, so that not only Europe but also Russia suffers if Russia's unreliability increases. For Europe, buying gas from more reliable suppliers at a price premium turns out to be generally more attractive than building strategic gas storage capacity.

${ }^{*}$ Corresponding author. Center for Economic Studies (Department of Economics) and KULeuven Energy Institute, Catholic University of Leuven (KULeuven), Naamsestraat 69, BE-3000 Leuven, Belgium. E-mail: joris.morbee@econ.kuleuven.be

${ }^{\dagger}$ Center for Economic Studies (Department of Economics) and KULeuven Energy Institute, Catholic University of Leuven (KULeuven), Naamsestraat 69, BE-3000 Leuven, Belgium. E-mail: stef.proost@econ.kuleuven.be

¥The authors thank the participants at the 2nd Enerday conference in Dresden in April 2007, the 9th IAEE European Energy Conference in Florence in June 2007, a discussion session at the European Commission - DG TREN in December 2008, and a CEPE seminar at ETH Zürich in May 2009, for their comments. We are also indebted to the editor and four anonymous referees for their constructive feedback. 


\section{INTRODUCTION}

In recent years, security of gas supply has been high on the political agenda in Europe. Gas import dependence of the European OECD bloc will increase from $45 \%$ in 2006 to $69 \%$ in 2030, according to the IEA (2008) Reference Scenario. Russia plays a crucial role, given that it already supplies more than half of Europe's gas imports and that it has the largest proven natural gas reserves in the world (BP, 2006-2008). ${ }^{1}$ This has been a source of increasing political concern, especially since 2006, when Russian gas export monopolist Gazprom launched an effort to increase the gas prices paid by Russia's neighboring states, as shown in Table 1 . The price conflict in Ukraine sparked strong political reactions in Europe, because it led to

Table 1: Gas prices for Russia's neigboring states, in USD per tcm

\begin{tabular}{lccc}
\hline Country & $\begin{array}{c}\text { Price on } \\
\text { Dec 31, 2005 }\end{array}$ & $\begin{array}{c}\text { Increased price } \\
\text { demanded by } \\
\text { Gazprom }\end{array}$ & $\begin{array}{c}\text { Price on } \\
\text { Jan 1, 2007 }\end{array}$ \\
\hline Ukraine & 50 & 230 & 130 \\
Belarus & 46 & 200 & 100 \\
Georgia & 100 & 235 & 235 \\
Moldova & 80 & (unknown) & 170 \\
\hline
\end{tabular}

Note: $\mathrm{tcm}=$ thousand cubic meters. Source: Press sources (2006)

interruptions of gas supplies to Europe in the beginning of 2006 and 2009. Energy supply security and in particular the potential unreliability of Russian gas imports became an important topic at EU summits and G8 meetings, and in bilateral discussions with Russia. After the second conflict in January 2009, Czech Prime Minister Topolanek - then President of the EU - even stated explicitly that "the EU must weaken its dependence on Russian gas imports" (IHT, Jan 28, 2009). ${ }^{2}$

\footnotetext{
${ }^{1}$ In this paper, the terms Europe and European refer to the EU-27 plus Norway, Switzerland and Iceland, unless indicated otherwise.

${ }^{2}$ It should be noted that the relation between Russia and Europe is very different from the relation between Russia and its neigboring states, which, before the price increase, were receiving gas from Russia at prices below netback parity. In addition, it is suspected that Russia's price increases in neighboring states are a prelude to deregulation of Russia's domestic gas market, which currently also has below-market prices. On the other hand, Russian gas prices for Europe in 2006 were already in line with the prices in the middle column of Table
} 
This paper provides an economic perspective on Russia's strategic position in the European gas market by answering the following two research questions:

1. What is the potential impact of Russian unreliability on the European gas market, and how does this affect European gas import decisions?

2. To what extent should Europe invest in gas storage capacity to mitigate the effects of potential Russian unreliability?

We study long-term gas contracting in a non-cooperative setting, using a partial equilibrium model of the European gas market, with differentiated competition between one potentially unreliable 'dominant firm' (Russia) and a reliable 'competitive fringe' of other nonEuropean import suppliers. Russia's potential unreliability is modeled by assuming that there is a probability $\delta$ that Russia does not comply with the long-term contracts it has signed: with probability $\delta$, Russia 'defaults' and withholds supply to increase its price to monopolistic levels for a duration of 4 months. The numerical analysis in this paper shows that it is not optimal for Russia to cut gas supplies to Europe completely during a crisis: rather, one can expect Russia to reduce its gas supplies by roughly $40 \%$ during the 4 months, thereby temporarily increasing gas prices by roughly $40 \%$. More importantly, the analysis shows that not only Europe but also Russia suffers when Russia's probability of default $\delta$ increases. Indeed, as Russia becomes - or is perceived as - more unreliable, Europe procures a larger volume of long-term gas import contracts from the competitive fringe. This way, Europe makes itself less dependent on Russia and therefore less vulnerable in the event of Russian withholding. With increasing Russian unreliability, the volume of long-term gas import contracts with Russia decreases while Russia has to grant an ever higher discount in its contracts. The resulting negative impact on Russia's profits is not sufficiently counterbalanced by the gains it makes in case it does not comply with its contracts. As a result, Russia's expected profits are found

1, which made Europe a profitable and important customer for Russia. Given that, in addition, Gazprom was trying to enter the downstream European gas market, Russia was unlikely to act in the same way towards Europe as it did towards Ukraine. Nevertheless, as a result of the Ukrainian gas crises, European politicians and gas consumers clearly started questioning the reliability of Russia as a gas supplier. 
to decrease as Russia's unreliability increases. As mentioned before, investments in strategic gas storage capacity can reduce Europe's vulnerability. However, the numerical simulations show that strategic storage capacity is only attractive for Europe if Russian unreliability is high ( $\delta$ of more than $30 \%$ ) and storage capacity costs are reduced by a factor 3 to 4 compared to typical current cost levels.

Earlier papers have studied Russian gas imports into Europe from different perspectives. Hirschhausen et al. (2005) focus on the strategic interaction between Russia and transit countries such as Ukraine and Belarus. Grais and Zheng (1996) analyze the quantity, price and transit fee of gas contracts between Russia and Europe, in a hierarchical three-stage Stackelberg game in which Russia is the leader, followed by the transit country, which in turn is followed by the response of European demand (factoring in a potential alternative gas supplier). They study the impact of exogenous shocks, e.g. an exogenous change in the preference for Russian gas over other gas, and they mention reliability as a potential cause of such a shock. Our model has a non-cooperative multi-stage structure similar to Grais and Zheng (1996), but goes a step further by explicitly examining how reliability affects the demand for Russian gas compared to gas from other suppliers: a demand shift resulting from a change in (un-)reliability is an endogenous effect in our model. In addition, our paper investigates investment in strategic gas storage capacity. On the flip side, to keep the paper focused, we do not model the strategic behavior of transit countries.

The effect of a Russian supply interruption has recently been examined by Hartley and Medlock (2009): as part of their analysis of potential futures for Russian gas exports, they use a comprehensive numerical dynamic spatial equilibrium model to study the global supply chain repercussions of a scenario in which Russia withholds roughly one third of its gas supplies to Europe during a 4-month period. Hartley and Medlock (2009) model the interruption as a deterministic shock with exogenous size. In contrast, in our model, the size of the shock is endogenous, and more importantly, there is uncertainty as to whether the shock will occur. Our model provides an analytical study of how the anticipation of a possible shock 
- in other words, the perception of unreliability - alters strategic decisions. Our methodology for modeling unreliability is taken from the pioneering paper by Nordhaus (1974), who analyzes oil supply interruptions using a model with two regimes: a normal regime and a supply interruption regime, each with its probability. Like Nordhaus (1974), we investigate the option of investing in storage capacity. ${ }^{3}$ However, in addition, our model analyzes the contrast between an unreliable supplier and a reliable competitive fringe. In this setting, gas import contracts with the reliable competitive fringe and investments in storage capacity are (imperfect) substitutes.

Since our paper studies long-term gas import contracts, there are similarities with the literature that deals with these contracts (such as Boucher et al., 1987, and Neuhoff and Hirschhausen, 2005) and with the 'hold-up' literature, such as Hubert and Ikonnikova (2004). However, an important difference between the approach in this paper and the approach of Hubert and Ikonnikova (2004) or Ikonnikova and Zwart (2009) is that the latter two papers use cooperative game theory and explicitly model the negotiation/bargaining between the various parties. Our paper, in contrast, describes the gas market in a non-cooperative setting with quantity competition, following the seminal work of Mathiesen et al. (1987), several wellknown analyses such as Golombek et al. (1995, 1998), Boots et al. (2004) and more recent work such as Holz et al. (2008) and Lise et al. (2008). ${ }^{4}$ Most of this literature considers European consumers as price-takers with linear demand, which is also the approach taken in this paper. $^{5}$

On a broader microeconomic level, the analysis of this paper fits into the literature on differentiated competition. Indeed, as will be shown in Section 3, the contrast of a potentially

\footnotetext{
${ }^{3}$ Nordhaus (1974) also investigates import taxes, but it turns out that storage is the most specific response to supply security concerns. In this paper, storage shall therefore be used as the exemplification of a broader range of policy measures (e.g. import taxes, rationing, subsidies for renewable energy, etc.).

${ }^{4}$ Note in particular that an analysis of long-term contracts is not considered inconsistent with non-cooperative modeling. On the contrary, Boots et al. (2004) also use (non-cooperative) Cournot-Nash modeling, which they justify by writing "competition can be expected to take place through quantities, since long-term take-or-pay contracts still prevail in the natural gas market" (Boots et al., 2004, p.74).

${ }^{5}$ However, unlike this paper, the models of Boots et al. (2004) and Golombek et al. $(1995,1998)$ analyze a segmentation of the European market, based on country and/or type of consumer and/or season. Our paper has only one aggregate demand curve. Note that Holz et al. (2008), as an exception, use non-linear demand curves.
} 
unreliable gas import supplier (in this case: Russia) and a set of reliable import suppliers (in this case: the competitive fringe of other non-European import suppliers), results in a market structure similar to differentiated competition. Singh and Vives (1984) for example, compare Cournot and Bertrand competition in differentiated duopoly, while Gaudet and Moreaux (1990) do the same for the particular case of nonrenewable natural resources. The main contribution of our paper is that it introduces the notion of unreliability directly into the market structure of the European gas market.

The paper is organized as follows. Section 2 describes the set-up and main assumptions of the model. Section 3 develops the analytical solution for the computation of the equilibria. Section 4 presents the numerical results. Finally, Section 5 returns to the initial research questions.

\section{MODEL OF THE EUROPEAN IMPORTED GAS MAR- KET}

\subsection{European demand, domestic supply, and objective function}

Europe is modeled as a large number of uncoordinated gas consumers and domestic gas producers, with an overarching government that can decide to invest public funds in gas storage capacity. We assume Europe is a price-taker with a linear long-run inverse demand curve for gas:

$$
p(q)=\alpha+\beta q
$$

European domestic producers supply an exogenous and fixed quantity $q_{D}$, and the remaining excess demand $q-q_{D}$ needs to be satisfied by non-European imports. Short-run demand is also linear, but with a steeper slope $\beta_{S R}$ :

$$
p_{S R}(q)=p^{*}+\beta_{S R} \cdot\left(q-q^{*}\right)
$$

with $\left(p^{*}, q^{*}\right)$ representing the long-run equilibrium. 
We assume that decisions on long-term gas import contracts and publicly financed strategic storage capacity investments are based on a combination of the interests of importers, end-consumers, domestic producers and taxpayers. We therefore assume that Europe maximizes the expected total 'European surplus' $E[S]$ :

$$
\max E[S] \quad \text { with } \quad S=C S+\Pi_{D}-G
$$

where $C S$ is the consumer surplus, ${ }^{6} \Pi_{D}$ represents the profits of domestic producers, and $G$ is the public expenditure on gas storage capacity investments. $-G$ represents the interests of the recipients of marginal expenditures out of general government revenue. Note that equation (3) assumes risk-neutrality. Annex D deals with the case of European risk aversion.

\subsection{Non-European gas import suppliers}

Excess demand needs to be satisfied by signing long-term import contracts with non-European import suppliers. We assume that the non-European import suppliers have a dominant firmcompetitive fringe structure. ${ }^{7}$ Russia is the 'dominant firm' and the other non-European gas import suppliers are grouped together as the 'competitive fringe'.

Russia is modeled as a monolithic entity, i.e. no difference is made between the Russian state and the gas exporter Gazprom. Russia is assumed to be a risk-neutral profit maximizer. Russia is modeled to be unreliable: once the long-term contracts have been signed, there is a probability $\delta$ that Russia temporarily does not comply with its previous supply commitments, i.e. Russia 'defaults'. Conversely, there is a probability $(1-\delta)$ that Russia complies with its long-term contracts during the entire period. All participants know the parameter $\delta$ upfront. $^{8}$ Russia's long-run marginal costs of production are assumed constant at $c_{R}$.

\footnotetext{
${ }^{6}$ For the sake of simplicity, our model does not go to the level of individual end-consumers such as households, industrial users and power generators. Therefore, the term CS, as we will compute it based on demand curve (1), is in fact the importer surplus. In practice, this surplus is somehow divided into importers' profits on the one hand and end-consumer surplus on the other hand. We will not make that distinction, since it depends on market power and regulation in individual countries. We will simply refer to $C S$ as 'consumer surplus'.

${ }^{7}$ This fairly standard model of industrial organization is described in multiple textbooks, e.g. Carlton and Perloff (2000, Chapter 4).

${ }^{8}$ Hence, $\delta$ is exogenous, and there is perfect and complete information about it. The rationale for exogeneity of $\delta$ is that Russia's decision-makers are also aware of the potential unreliability of the Russian state, and that they do not have full control over Russia's image of unreliability, nor over Russia's actual behavior over the
} 
The competitive fringe is a diversified set of current or potential future non-European gas import suppliers, including both pipeline and LNG supplies. Therefore, we assume that - as a group - the competitive fringe is reliable: even if Russia defaults, the competitive fringe delivers the originally promised contract quantity $q_{0}$ at the originally promised contract price $p_{0}$. This requires two assumptions. First, we assume that the long-term gas import contracts between Europe and the competitive fringe are not indexed on any gas spot market price, which would rise sharply in the event of Russian default. In practice, this condition is fulfilled since most current long-term gas import contracts contain little or no indexation on gas spot market prices. Second, we assume that the competitive fringe players do not deviate from their contracts. This is a major assumption, which can be justified by the difference in scale between Russia and each of the other non-European import suppliers. Each of the other nonEuropean import suppliers has much less incentive to be unreliable because the market impact of each of them is much smaller. In addition, a supplier who is perceived as unreliable could face the threat of being replaced by another supplier in the long term. Russia, on the other hand, is hard to replace completely in the long term, even if it behaves unreliably. As we will see below in Section 2.3, the reliability of the competitive fringe does not mean that in the event of Russian default - there would be price discrimination between end-consumers of Russian gas and end-consumers of gas from the competitive fringe. There will be only one single end-consumer price. ${ }^{9}$ However, the rents that result from the compliance of the competitive fringe in the event of Russian default accrue to European importers. Therefore, the most important implication of our assumption is that these rents are part of the European surplus function $S$ in equation (3), and are not part of the profits of the competitive fringe. As for costs, we assume that the long-run marginal cost curve of the competitive fringe is linearly

entire period for which gas contracts are signed. For instance, although Russia never cut gas supplies to Europe during the Ukrainian gas conflicts, the conflict nevertheless led to an increased perception of unreliability in Europe. As we will see later, our model shows that if Russia had full control over its unreliability, it would be optimal for Russia to be perfectly reliable $(\delta=0)$. Since we want to study the effects of increased unreliability (whether it is pursued deliberately or not), we make $\delta$ exogenous. In Section 5, we mention a different approach which could lead to an endogenous $\delta$.

${ }^{9}$ One could imagine offering interruptible contracts to industrial consumers at a discount. We will not consider that option in this paper. 
increasing: $c_{0}+d_{0} q_{0}$ (with $q_{0}$ the volume of long-term gas import contracts supplied by the competitive fringe, and $c_{0}, d_{0}$ positive constants).

The above-mentioned long-run marginal cost functions (i.e. $c_{R}$ for Russia, and $c_{0}+d_{0} q_{0}$ for the competitive fringe) include not only production costs, but also transportation costs. The calibration for the numerical simulations of Section 4 will take this into account. ${ }^{10}$ Finally, since this paper analyzes the gas market on an aggregated European level and does not model gas delivery to end-consumers, distribution costs are irrelevant.

\subsection{Structure of the game}

The interaction between Europe, Russia and the competitive fringe, is modeled as a game in three stages. Figure 1 explains the different stages of the game. In a nutshell: in Stage 1 Europe decides how much it invests in strategic gas storage capacity; Stage 2 is the stage in which Europe signs long-term gas import contracts with Russia and the competitive fringe; Stage 3 consists in the execution of the long-term gas import contracts, in which Russia may or may not comply with the long-term contracts it has signed. We represent the imported gas quantities by $q_{R, 1}$ (Russia complies with long-term contracts), $q_{R, 2}$ (Russia defaults) and $q_{0}$ (competitive fringe). The corresponding prices are denoted $p_{R, 1}, p_{R, 2}$ and $p_{0}$.

Before describing each of the stages in detail, it is important to note how the stochastic outcome of Stage 3 influences the strategic interaction in Stage 2. Figure 2 illustrates how Europe and Russia factor the expected value of Stage 3 pay-offs into their decisions in Stage 2. In Stage 3, European surplus is either $S=S_{1}$ or $S=S_{2}$ depending on whether Russia complies with its long-term contracts or not. In Stage 2, Europe therefore tries to maximize the expected surplus $E[S]$. This maximization problem can be translated into demand functions for Russian and other long-term gas import contracts by finding - for given long-term

\footnotetext{
${ }^{10}$ Note that, while certain parts of the transportation cost can be estimated reasonably well (e.g. LNG shipping from overseas suppliers to Europe), transportation sometimes relies on transit countries (e.g. Ukraine), which leads to additional complexity. For example, Hirschhausen et al. (2005) explicitly study the strategic considerations involved in gas transport from Russia to Europe via transit countries Ukraine and Belarus. While these considerations are important, our paper focuses on the strategic interaction between Europe and its import suppliers. We use OME (2002) estimates of the transit fees.
} 


\section{Figure 1: Timeline and decisions in the model proposed in this paper}

\begin{tabular}{|c|c|c|c|}
\hline & Timeline & & Decisions (decision-makers in italics) \\
\hline $\begin{array}{l}\text { Stage 1: } \\
\text { Storage capacity } \\
\text { investment } \\
\text { decision }\end{array}$ & & & Europe decides construction of strategic gas storage capacity $q_{S}$ \\
\hline $\begin{array}{l}\text { Stage 2: } \\
\text { Signing long- } \\
\text { term gas import } \\
\text { contracts }\end{array}$ & & & $\begin{array}{l}\text { 'Dominant firm - competitive fringe' game, with Europe as price-taker: } \\
\left(2 \text { Competitive fringe decides to promise gas contract quantity } q_{0}\right. \\
\text { (3) Europe's inverse demand curves determine gas contract prices } p_{R, 1} \\
\text { and } p_{0} \text { in response to } q_{R, 1} \text { and } q_{0}\end{array}$ \\
\hline $\begin{array}{l}\text { Stage 3: } \\
\text { Execution of } \\
\text { contracts }\end{array}$ & $\begin{array}{l}\text { Probability } \\
(1-\delta)\end{array}$ & Probability & $\begin{array}{l}\text { 'Nature' decides whether Russia defaults or not (i.e., this is a } \\
\text { probabilistic event) }\end{array}$ \\
\hline Outcome & $\begin{array}{l}\text { Case } 1 \text { - Russia } \\
\text { complies with long- } \\
\text { term contracts: } \\
\text { - Russia delivers } \\
q_{R, 1} \text { as promised } \\
\text { - Competitive } \\
\text { fringe delivers } q_{0}\end{array}$ & $\begin{array}{l}\text { Case 2 - Russia } \\
\text { 'defaults': } \\
\text { - Russia delivers } \\
q_{R, 2}\left(<q_{R, 1}\right) \\
\text { - Competitive } \\
\text { fringe delivers } q_{0}\end{array}$ & \\
\hline
\end{tabular}

gas contract prices - the optimal long-term gas contract quantities that maximize Europe's expected surplus $E[S]$ in Stage 3. In the 'dominant firm - competitive fringe' game in Stage 2, dominant firm Russia sets the optimal gas contract quantity to maximize its expected profits $E\left[\Pi_{R}\right]$ in Stage 3, taking into account the supply curve of the competitive fringe and Europe's above-mentioned demand functions for Russian and other long-term gas import contracts. European demand for long-term gas import contracts will turn out to be differentiated between gas import contracts from Russia and gas import contracts from the competitive fringe, because their effect in Stage 3 is different. The rest of this section describes the three stages in more detail.

In Stage 1, Europe decides to foresee a quantity $q_{S}$ (in bcm, i.e. billion cubic meters) of strategic gas storage capacity, to be used as a buffer in case of withholding of gas supply by Russia. Given the long lead times involved in the development of storage sites, this decision cannot be postponed until it is known whether Russia will comply with its contracts or not 
Figure 2: Impact of the stochastic outcome of Stage 3 on the strategic interaction in Stage 2

\begin{tabular}{|c|c|}
\hline $\begin{array}{l}\text { Stage 3: } \\
\text { Execution of } \\
\text { contracts }\end{array}$ & $\begin{array}{l}\text { - Case 1 - Russia complies with long-term contracts: } \\
\text { - Europe obtains surplus } S=S_{1} \\
\text { - Russia obtains profits } \Pi_{R}=\Pi_{R, 1} \\
\text { - Case } 2 \text { - Russia 'defaults': } \\
\text { - Europe obtains surplus } S=S_{2} \\
\text { - Russia obtains profits } \Pi_{R}=\Pi_{R, 2}\end{array}$ \\
\hline $\begin{array}{l}\text { Stage 2: } \\
\text { Signing long- } \\
\text { term gas import } \\
\text { contracts }\end{array}$ & $\begin{array}{l}\text { Europe: } \\
\text { - Europe expects to obtain surplus } E[S]=(1-\delta) S_{1}+\delta S_{2} \text { in Stage } 3 \\
\text { - Therefore, Europe's demand functions for gas import contracts in } \\
\text { Stage } 2 \text { can be determined by finding the contract quantities } q_{R, 1} \text { and } \\
q_{0} \text { that maximize expected surplus } E[S] \text { for given prices } p_{R, 1} \text { and } p_{0} \\
\text { - Because gas import contracts from Russia and from the competitive } \\
\text { fringe have a different effect in Stage } 3 \text {, Europe has a different } \\
\text { willingness-to-pay for gas import contracts from Russia and from the } \\
\text { competitive fringe } \\
\text { - Russia: } \\
\text { - Russia expects to obtain profits } E\left[\Pi_{R}\right]=(1-\delta) \Pi_{R, 1}+\delta \Pi_{R, 2} \text { in } \\
\text { Stage } 3 \\
\text { - In the 'dominant firm - competitive fringe' game in Stage 2, Russia } \\
\text { chooses its contract quantity } q_{R, 1} \text { to maximize expected profits, given } \\
\text { (i) the supply curve of the competitive fringe, and (ii) the European } \\
\text { demand functions mentioned above }\end{array}$ \\
\hline
\end{tabular}

Note: the actions of the competitive fringe are not included in this diagram because their profits are not different between Case 1 and Case 2, and because they behave non-strategically in Stage 2

(i.e. it cannot wait until Stage 3). Furthermore, in our model, the storage capacity investment decision takes place before decisions are made regarding the amounts of long-term gas imports that are contracted from Russia and the competitive fringe (i.e. before Stage 2). The reason is that investment in storage capacity is a decision that Europe can make unilaterally. By making the storage capacity investment decision in a separate stage upfront (Stage 1), Europe gives its storage capacity investment decision an advantageous Stackelberg leadership position in the strategic game with its gas import suppliers. In making the decision about storage capacity investment, Europe takes into account the strategic behavior of Stage 2, and it has perfect and complete information to do so.

In Stage 2 Europe signs long-term gas import contracts with Russia and with the competitive fringe. Our approach is non-cooperative, with Europe as a price-taker in a 'dominant firm - competitive fringe' model of the long-term gas import contract market. Russia, as the 
dominant firm, puts a quantity $q_{R, 1}$ (in bcm per year) on the European market, for which it receives a price $p_{R, 1}$ (in EUR per tcm, i.e. EUR per thousand cubic meters). ${ }^{11}$ In making its decision, Russia already takes into account the subsequent decision of the competitive fringe, who put a quantity $q_{0}$ (in bcm per year) on the market, for which they receive a price $p_{0}$ (in EUR per tcm). The prices $p_{R, 1}$ and $p_{0}$ are the response of the European inverse demand functions to the quantities $q_{R, 1}$ and $q_{0}$. The quantity-price pairs $\left(q_{R, 1}, p_{R, 1}\right)$ and $\left(q_{0}, p_{0}\right)$ represent the long-term gas import contracts signed between Europe and Russia, and between Europe and the competitive fringe, respectively. Because of Russian unreliability, the prices $p_{R, 1}$ and $p_{0}$ do not need to be the same. Although there are separate inverse demand functions for Russian and other gas - resulting from the behavior of importers - the end-consumers face a single price for gas and cannot choose their own mix of reliable and non-reliable gas. There is a single end-consumer price in each of the two states of the world in Stage 3.

Stage 3, the final stage of the game, is the execution of the long-term gas import contracts signed in Stage 2. Stage 3 is the stage that results in actual pay-offs for the participants to the game. We study one representative year: although the import contracts and storage capacity investment decisions are long-term decisions that will hold for multiple years, all volumes and monetary pay-offs in Stage 3 are shown as annual amounts. In a representative year, there is a probability $1-\delta$ that Russia honors its commitments, and effectively delivers $q_{R, 1}$ at a price $p_{R, 1}$. This is 'Case 1' (Russia complies with long-term contracts). Figure 3 illustrates Case 1 graphically. $q_{D}$ is the gas supply from European domestic producers, which is assumed to be exogenous and fixed (inelastic). The shaded area, $S_{1}$, is the European surplus according to equation (3), but without taking any storage capacity investments into account. ${ }^{12}$ Endconsumers pay a single price corresponding to $p^{*} \in\left[p_{R, 1}, p_{0}\right]$, such that demand at price $p^{*}$ is exactly equal to $q_{0}+q_{R, 1}$. In a representative year, there is also a probability $\delta$ of default, in

\footnotetext{
${ }^{11}$ Note that $\mathrm{bcm}$ per year is consistently used for quantities, while EUR / $\mathrm{tcm}$ is consistently used for price. The alternative use of bcm and tcm makes the resulting quantity and price numbers conveniently end up in the 0 -200 range.

${ }^{12}$ For the sake of simplicity, we assume that the domestic suppliers have zero cost, hence the shaded area for $q \in\left[0, q_{D}\right]$ in Figure 3 extends all the way down to the horizontal axis. A non-zero cost would merely constitute a uniform shift of the European surplus function, which would not affect results.
} 
Figure 3: Demand and supply in Case 1 Russia complies with long-term contracts

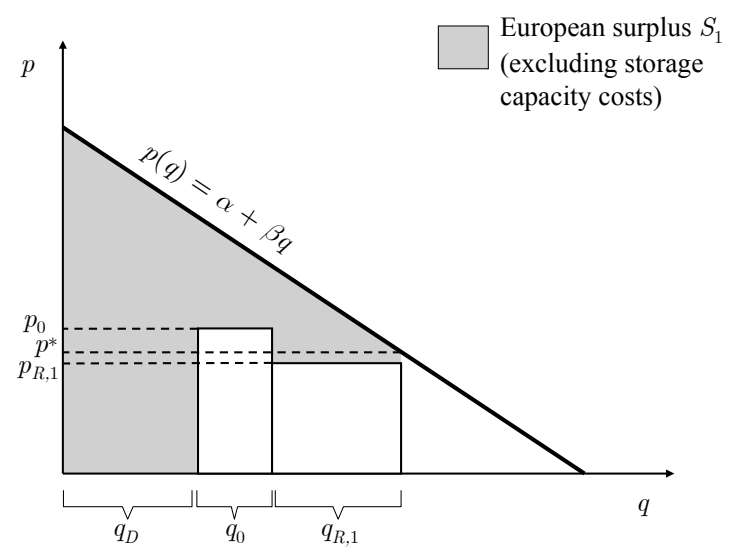

Figure 4: Demand and supply in Case 2 Russia 'defaults'

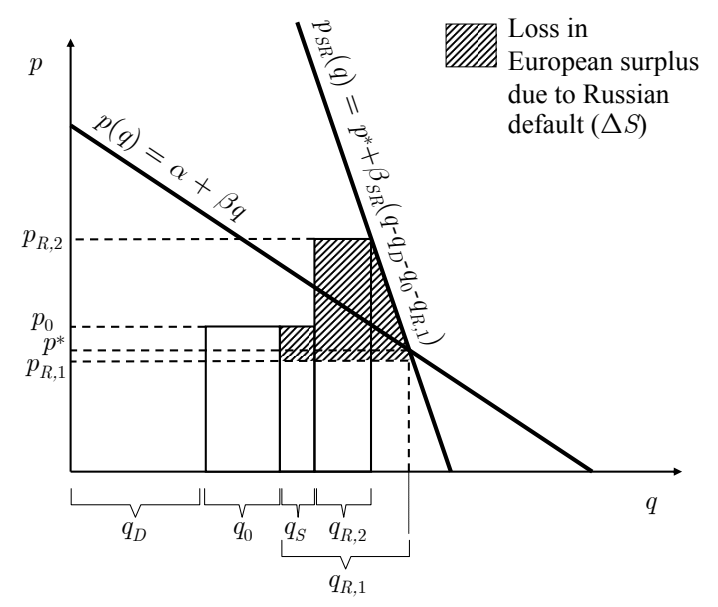

which case Russia withholds supply to maximize short-run profits. This is 'Case 2' (Russia defaults), which is depicted in Figure 4. Assuming that neither $q_{D}$ nor $q_{0}$ can increase in the short run, Russia can set $q_{R, 2}<q_{R, 1}$, for which it can command a price $p_{R, 2} \gg p_{R, 1}$. Note that this price is derived from the short-run demand curve (2). Europe responds by cutting consumption and using the maximum amount of stored gas, which is constrained by the storage capacity $q_{S}$ chosen in Stage 1 . The storage capacity investment only covers the cost of the storage facility and the capital cost of the unused gas, but not the purchase price of the stored gas itself. The gas withdrawn from the storage will therefore need to be replaced for future crises, and we assume that this can be done at some point at a price equal to $p_{0}$. Effectively, the price of using gas from the storage is therefore $p_{0}$ (in addition to storage capacity costs, which are sunk). The competitive fringe always delivers $q_{0}$ at price $p_{0}$, whatever happens in Stage 3. As before, this does not mean that identical end-consumers would pay different prices in the event of Russian default. Since the marginal unit of gas import supply in the short run in case of Russian default has a cost $p_{R, 2}$ (because only Russia could increase supply), the 'marginal' price for end-consumers should correspond to $p_{R, 2}$. While this does create a rent $\left(p_{R, 2}-p_{0}\right) q_{0}$, the rent is part of the European surplus. ${ }^{13}$ In total,

\footnotetext{
${ }^{13}$ Both in Case 1 and in Case 2, there may be a rent (or loss) for importers, because the price paid by end-
} 
the European surplus in case of Russian default is lower than $S_{1}$ from Figure 3. Figure 4 shows $\Delta S$, the loss in European surplus due to Russian default. This loss is discussed in more detail in equation (8) in the next section.

The three stages of the game represent three distinct decisions. We assume that this 3 -stage game is played once. In practice, the game is obviously repeated after a number of years, but because the lead times for gas projects are very long, we do not consider the repeated game. Finally, if Russia 'defaults' (probability $\delta$ ), the assumption is that this happens only during a fraction $\tau$ of the year. For the remaining fraction $(1-\tau)$ of the year, Russia respects $q_{R, 1}$ and $p_{R, 1}$. This is comparable with the approach taken by Hartley and Medlock (2009): in their scenario of a Russian supply interruption, they consider a supply reduction which lasts for 4 months in the year 2010. In our model, this corresponds to setting $\tau=4 / 12 .{ }^{14}$ If Russia defaults, Figure 4 represents the supply situation during a fraction $\tau$ of the year, while Figure 3 represents the supply situation during the remaining fraction $(1-\tau)$ of the year. ${ }^{15}$ The volumes $q_{D}, q_{0}, q_{S}, q_{R, 2}$ shown in Figure 4 should be interpreted as annualized volumes. ${ }^{16}$ This means, consumers ( $p^{*}$ in Case 1 , and $p_{R, 2}$ in Case 2 ) does not correspond to the average price paid by the importers (a weighted average of $p_{0}$ and $p_{R, 1}$ in Case 1, and a weighted average of $p_{0}$ and $p_{R, 2}$ in Case 2). This positive or negative rent is treated as an integral part of European surplus. In the simplest situation, the rent takes the form of windfall profits (or losses) for gas importers. However, more realistically, we can expect that European governments would intervene and take measures that would redistribute the rents (or losses) to end-consumers, e.g. through non-linear tariffs. One example of non-linear tariffs during a Russian default (Case 2), would be a measure that allows all households a rationed share of $q_{0}+q_{S}$ at a price corresponding to $p_{0}$, while the remaining gas imports are priced according to $p_{R, 2}$. This measure would distribute the rent $\left(p_{R, 2}-p_{0}\right) q_{0}$ to end-consumers whilst ensuring that demand is reduced to the available gas quantity $q_{D}+q_{0}+q_{S}+q_{R, 2}$ because the 'marginal' price perceived by households is still $p_{R, 2}$.

${ }^{14}$ One could argue that this is a relatively high number given e.g. the fact that the Ukrainian gas crises lasted only a few days/weeks compared to a history of decades of uninterrupted gas supply. However, as stated before, the model in this paper analyzes a situation that is very different from the Ukrainian gas crisis, and we want to be sufficiently conservative. The impact of a lower value of $\tau$ would be that less weight would be given to $\Delta S$ in the computation of Europe's expected surplus (equation 9). As a result, higher values of $\delta$ would be needed to reach the effects observed in the simulations in Section 4.

${ }^{15}$ Obviously, if Russia complies with its contracts, then Figure 3 represents the supply situation during the entire year.

${ }^{16}$ The notion 'annualized' in this paper means that the quantity is extrapolated to an entire year. For example, suppose Europe has a contract with Russia for $q_{R, 1}=120 \mathrm{bcm}$ per year, i.e. $10 \mathrm{bcm}$ per month. During a 4-month crisis $(\tau=4 / 12)$, Russia reduces supply from $10 \mathrm{bcm}$ per month to $6 \mathrm{bcm}$ per month. In that case, we will have $q_{R, 2}=12 \times 6=72 \mathrm{bcm}$ per year. Note however, that the crisis lasts for only 4 months, so the volume supplied by Russia during the crisis is only $4 \times 6=24 \mathrm{bcm}$. However, to make the magnitude of $q_{R, 1}$ and $q_{R, 2}$ comparable, we choose to represent annualized amounts in the figures and formulas: everything is expressed per year. 
in particular, that in order to have access to an annualized storage withdrawal volume of $q_{S}$ during a Russian default (which lasts for a fraction $\tau$ of the year), a storage capacity of only $\tau q_{S}$ is needed. Furthermore, the total European surplus $S_{2}$ during a representative year in the event of Russian default is given by:

$$
S_{2}=(1-\tau) S_{1}+\tau\left(S_{1}-\Delta S\right)=S_{1}-\tau \Delta S
$$

In summary, our model describes Russia's unreliability as a potential 'default' event, with a probability $\delta$ of default. ${ }^{17}$ The model takes into account two ways for Europe to escape from the unreliability of Russian gas supplies: on the one hand, diversification by signing long-term contracts with the competitive fringe, and on the other hand, investments in strategic storage capacity. ${ }^{18}$ The next section solves the model analytically.

\section{ANALYTICAL SOLUTION}

We now analyze the game described in Section 2 using backward induction. Figure 5 gives an overview of the successive steps in the solution procedure. This section discusses each of the steps in detail.

\subsection{Stage 3: Execution of contracts}

Stage 3 determines the pay-offs for Europe, Russia and the competitive fringe. There are two possible cases: either Russia complies with the long-term contracts it has signed (Case 1) or Russia 'defaults' (Case 2). We will compute the pay-offs of Europe and Russia in each of these two cases.

\footnotetext{
${ }^{17}$ The model thus accounts for uncertainty in Russia's behavior (i.e. deliberate supply withholding and price increases), as opposed to technical uncertainty. Technical uncertainty is the risk of a sudden supply interruption because of technical failure of e.g. gas pipeline systems. Technical uncertainty is not considered in this paper.

${ }^{18}$ Similarly, the section on supply security in the energy policy communication of the European Commission (2007) emphasizes strategic storage and diversification.
} 
Figure 5: Solution of the model using backward induction

\begin{tabular}{|c|c|c|}
\hline & $\begin{array}{l}\text { Solution } \\
\text { step }\end{array}$ & Analysis \\
\hline $\begin{array}{l}\text { Stage 3: } \\
\text { Execution of } \\
\text { contracts }\end{array}$ & (1) & $\begin{array}{l}\text { - Compute pay-offs in Case 1: } \\
\text { - European surplus } S_{1}\left(q_{R, 1}, q_{0}, p_{R, 1}, p_{0}\right) \\
\text { - Russian profits } \Pi_{R, 1}\left(q_{R, 1}, p_{R, 1}\right) \\
\text { - Compute pay-offs in Case } 2 \text { : } \\
\text { - European surplus } S_{2}\left(q_{R, 1}, q_{0}, p_{R, 1}, p_{0}, q_{S}, q_{R, 2}, p_{R, 2}\right) \\
\text { - Russian profits } \Pi_{R, 2}\left(q_{R, 1}, p_{R, 1}, q_{R, 2}, p_{R, 2}\right) \\
\text { with } q_{R, 2}=q_{R, 2}\left(q_{R, 1}, q_{0}, q_{S}\right) \text { and } p_{R, 2}=p_{R, 2}\left(q_{R, 1}, q_{0}, q_{S}\right)\end{array}$ \\
\hline $\begin{array}{l}\text { Stage 2: } \\
\text { Signing long- } \\
\text { term gas import } \\
\text { contracts }\end{array}$ & 3 & $\begin{array}{l}\text { - Determine European demand functions for long-term gas import } \\
\text { contracts by finding the contract quantities } q_{R, 1}\left(p_{R, 1}, p_{0}, q_{S}\right) \text { and } \\
q_{0}\left(p_{R, 1}, p_{0}, q_{S}\right) \text { that maximize expected surplus } E[S] \text { for given prices } \\
p_{R, 1}, p_{0} \text { and given storage capacity } q_{S} ; \text { Use the result to compute the } \\
\text { inverse demand functions for gas import contracts: } p_{R, 1}\left(q_{R, 1}, q_{0}, q_{S}\right)\end{array}$ \\
\hline & (5) & $\begin{array}{l}\text { - Determine the non-strategic contract quantity setting behavior of the } \\
\text { competitive fringe, given a contract quantity decision by Russia: } \\
q_{0}\left(q_{R, 1}, q_{S}\right) \\
\text { - Determine the strategic contract quantity setting behavior of 'dominant } \\
\text { firm' Russia, for given storage capacity: } q_{R, 1}\left(q_{S}\right)\end{array}$ \\
\hline $\begin{array}{l}\text { Stage 1: } \\
\text { Storage capacity } \\
\text { investment } \\
\text { decision }\end{array}$ & (6) & $\begin{array}{l}\text { - Determine Europe's strategic storage capacity investment decision by } \\
\text { finding the optimal } q_{S} \text { that maximizes } E[S] \text {, given the anticipated } \\
\text { results of Stage } 2 \text { and Stage } 3\end{array}$ \\
\hline
\end{tabular}

Case 1: Russia complies with long-term contracts. In this case, the European surplus in a representative year corresponds to the shaded area $S_{1}$ in Figure 3:

$$
S_{1}=\alpha \cdot\left(q_{D}+q_{0}+q_{R, 1}\right)+\frac{1}{2} \beta \cdot\left(q_{D}+q_{0}+q_{R, 1}\right)^{2}-p_{0} q_{0}-p_{R, 1} q_{R, 1}-c_{S} \tau q_{S}
$$

This result is obtained by applying equation (3), or directly graphically from Figure 3 . The first two terms are simply the integration of the inverse demand curve (1) on the interval $\left[0 ; q_{D}+q_{0}+q_{R, 1}\right]$. The next two terms represent the expenditure on imported gas, taking into account that both Russia and the competitive fringe comply with their contracts. The last term is the yearly storage capacity cost $G=c_{S} \tau q_{S}$. In this expression, $c_{S}$ is the yearly constant marginal cost of gas storage capacity, expressed in EUR per tcm per year. One could interpret $G$ as the yearly rent to be paid for the storage site. Note that $G$ has to be paid whether or not the gas is actually withdrawn. 
Russia's profits in a representative year in Case 1 are:

$$
\Pi_{R, 1}=\left(p_{R, 1}-c_{R}\right) q_{R, 1}
$$

Case 2: Russia defaults. In this case, Russia does not supply $q_{R, 1}$ at $p_{R, 1}$, but delivers a lower quantity $q_{R, 2}$ at a higher price $p_{R, 2}$, for a fraction $\tau$ of the representative year. Since Russia's unilateral action comes as a surprise, the relation between $q_{R, 2}$ and $p_{R, 2}$ is determined by Europe's short-run demand curve (2), taking into account the mitigating effect of storage. Annex A derives Russia's optimal quantity and price:

$$
\begin{aligned}
q_{R, 2} & =-\frac{1}{2 \beta_{S R}}\left[p^{*}-\beta_{S R}\left(q_{R, 1}-q_{S}\right)-c_{R}\right] \\
p_{R, 2} & =\frac{1}{2}\left[p^{*}-\beta_{S R}\left(q_{R, 1}-q_{S}\right)+c_{R}\right]
\end{aligned}
$$

Remember that $\beta_{S R}<0$ and so the second term in the expression for $p_{R, 2}$ is a positive markup. Higher $q_{R, 1}$ or lower $q_{S}$ lead to higher vulnerability of Europe and therefore increase the potential monopoly price $p_{R, 2}$. In other words, the impact of Russian unreliability is larger when Russia has a larger market share to begin with (larger $q_{R, 1}$ ), or when Europe has less strategic gas storage capacity (lower $q_{S}$ ). The price $p_{R, 2}$ also increases with $p^{*}$, because $p^{*}$ is the starting point of the European price before Russian withholding.

The loss in European surplus during the Russian default can be derived from Figure 4:

$$
\begin{aligned}
\Delta S= & \left(p_{0}-p_{R, 1}\right) q_{S}+\left(p_{R, 2}-p_{R, 1}\right) q_{R, 2}+ \\
& +\left[\left(p^{*}-p_{R, 1}\right)+\frac{1}{2}\left(p_{R, 2}-p^{*}\right)\right]\left(q_{R, 1}-q_{S}-q_{R, 2}\right)
\end{aligned}
$$

$\Delta S$ applies only during the crisis, which lasts for a fraction $\tau$ of the year. Note that the value of $\Delta S$ is an annualized amount, like $q_{R, 2}$. The first term in equation (8) is the consumer surplus lost because gas from the storage is more expensive than the original contract with Russia. The second term is the consumer surplus lost because of the Russian price increase from $p_{R, 1}$ to $p_{R, 2}$. The last line in equation (8) is the loss of consumer surplus due to the unserved demand $q_{R, 1}-q_{S}-q_{R, 2}$. In Figure 4, this corresponds to the part of the striped area 
above the interval $q \in\left[q_{D}+q_{0}+q_{S}+q_{R, 2} ; q_{D}+q_{0}+q_{R, 1}\right]$. The total European surplus $S_{2}$ in a representative year in which Russia defaults can be obtained by substituting equation (8) into equation (4).

Russia's annualized profits during the 4-month crisis are $\left(p_{R, 2}-c_{R}\right) q_{R, 2}$. Russia's profits $\Pi_{R, 2}$ during an entire representative year in which Russia defaults are simply a weighted average of this amount and $\Pi_{R, 1}$, with weights $\tau$ and $1-\tau$, respectively.

Since $p^{*}=\alpha+\beta \cdot\left(q_{D}+q_{0}+q_{R, 1}\right)$, equations (5) through (8) can be easily expressed as a function of $q_{S}, q_{R, 1}, q_{0}, p_{R, 1}$ and $p_{0}$, i.e. the parameters of Stages 1 and 2. The results of these equations are taken into account by Europe and Russia when they make strategic decisions in Stage 2 .

\subsection{Stage 2: Signing long-term gas import contracts}

In Stage 2, Europe signs long-term gas import contracts with Russia and with the competitive fringe, i.e. the quantities $q_{R, 1}$ and $q_{0}$ and the prices $p_{R, 1}$ and $p_{0}$ are determined. In our noncooperative setting, Russia and the competitive fringe set quantities to maximize profits while taking into account Europe's inverse demand functions. In our solution procedure, we will first determine the European inverse demand functions for long-term gas import contracts, then determine the non-strategic decisions of the competitive fringe, and finally analyze the actions of 'dominant firm' Russia.

European inverse demand functions for long-term gas import contracts. For given longterm gas import contract prices $p_{R, 1}$ and $p_{0}$, European demand for long-term gas import is derived by finding the optimal quantities $q_{R, 1}$ and $q_{0}$ that maximize the expected value of European surplus $E[S]$ :

$$
E[S]=(1-\delta) S_{1}+\delta S_{2}=S_{1}-\delta \tau \Delta S
$$

with $S_{1}$ and $\Delta S$ as computed above. The resulting quantities $q_{R, 1}\left(p_{R, 1}, p_{0}, q_{S}\right)$ and $q_{0}\left(p_{R, 1}, p_{0}, q_{S}\right)$ will also be a function of stage- 1 decision variable $q_{S}$. By inverting the resulting expressions, 
we obtain the inverse demand functions. For the special case in which $\tau=1, q_{S}=q_{D}=0$ and $c_{R}=0$, the inverse demand functions are:

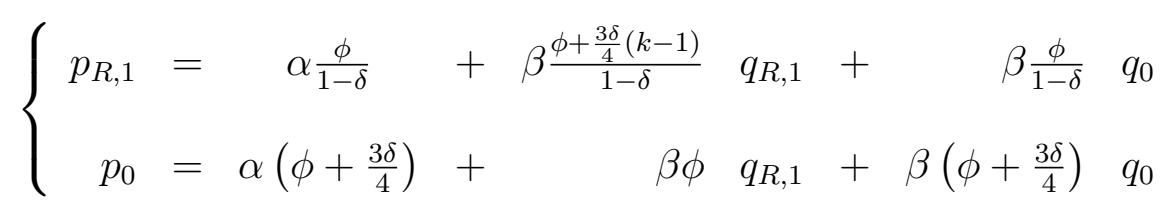

with $k=\beta_{S R} / \beta \gg 1$ and $\phi=1-\delta\left(3+k^{-1}\right) / 4>0$. These are the inverse demand functions for differentiated competition: because of Russian unreliability in Stage 3, the longterm gas import contract sector in Stage 2 is transformed into a two-good sector. The two differentiated goods are long-term gas import contracts with Russia on the one hand, and long-term gas import contracts with the competitive fringe on the other hand. The prices of these two goods can be different. The price obtained by Russia depends not only on the quantity set by Russia, but also on the quantity set by the competitive fringe (and vice versa). Note that the differentiation applies only at the contracting stage (Stage 2). Once the gas flows (Stage 3), the gas molecules are identical and there is by assumption no more differentiation at the final consumer's end. Since $\beta<0$, the partial derivatives $\partial p_{0} / \partial q_{0}, \partial p_{0} / \partial q_{R, 1}, \partial p_{R, 1} / \partial q_{0}$ and $\partial p_{R, 1} / \partial q_{R, 1}$ in equation (10) are all negative, as is expected for substitute goods.

A quick check is that for $\delta=0$ and hence $\phi=1$, there is no more differentiation between the two suppliers, and equations (10) reduce to equation (1). When $\delta>0$, we observe that $\partial p_{R, 1} / \partial q_{R, 1}<\partial p_{0} / \partial q_{0}$ (both are negative), meaning that Russia faces a more elastic demand curve than the competitive fringe, due to its unreliability. Likewise, $\partial p_{R, 1} / \partial q_{0}<\partial p_{0} / \partial q_{R, 1}$ : Russia's price drops more steeply in response to a quantity increase by the competitive fringe than vice versa. The effect of the asymmetry in Europe's preferences is that Russia's contract price $p_{R, 1}$ will be lower than $p_{0}$. In other words: when $\delta>0$, Russia needs to offer Europe a discount $\Delta p=p_{0}-p_{R, 1}>0$ due to its unreliability. Annex B shows that in general, for small values of $\delta$, the percentage discount is approximately given by:

$$
\frac{\Delta p}{p^{*}} \approx \frac{3}{4} \frac{\delta \tau}{\left|e_{S R}\right|}\left(\frac{q_{R, 1}}{q^{*}}\right)
$$

with $e_{S R}$ the short-run price elasticity of European demand for gas. Russia's discount increases with the probability $\delta$ and duration $\tau$ of possible interruptions, and with Europe's 
dependence on Russian long-term gas import contracts as a share of the total gas supply $\left(q_{R, 1} / q^{*}\right)$. Russia's discount decreases as Europe's short-run price elasticity of demand $\left|e_{S R}\right|$ increases (in absolute terms).

Non-strategic quantity decision by the competitive fringe. By definition, the competitive fringe behaves non-strategically and supplies long-term gas import contracts to Europe up to the point where the contract price equals the marginal cost of additional long-term gas imports. Setting $p_{0}$ from equation (10) equal to the marginal cost $c_{0}+d_{0} q_{0}$, we find: ${ }^{19}$

$$
q_{0}=\frac{\alpha\left(\phi+\frac{3}{4} \delta\right)-c_{0}}{d_{0}-\beta\left(\phi+\frac{3}{4} \delta\right)}+\frac{\beta \phi}{d_{0}-\beta\left(\phi+\frac{3}{4} \delta\right)} q_{R, 1}
$$

which provides us with the reaction of the competitive fringe as a function of the decision $q_{R, 1}$ by 'dominant firm' Russia.

Quantity decision by 'dominant firm' Russia. The 'dominant firm' Russia faces a residual (inverse) demand function $p_{R, 1}=p_{R, 1}\left(q_{R, 1}\right)$, which is found by substituting equation (12) in the expression for $p_{R, 1}$ in equation (10). Using the residual demand function, Russia's expected profits $E\left[\Pi_{R}\right]=(1-\delta) \Pi_{R, 1}+\delta \Pi_{R, 2}$ can be expressed as a function of $q_{R, 1}$ (and $\left.q_{S}\right)$. Russia chooses a long-term contract quantity $q_{R, 1}$ to maximize $E\left[\Pi_{R}\right]$ as a monopolist on the residual demand function. ${ }^{20}$ For the special case $\delta=0$ (and hence also $q_{S}=0$ ) we find

\footnotetext{
${ }^{19}$ Note that this is still for the special case in which $\tau=1, q_{S}=q_{D}=0$ and $c_{R}=0$. The procedure for the general case is completely analogous.

${ }^{20}$ This is the standard textbook solution to the 'dominant firm - competitive fringe' model (see e.g. Carlton and Perloff, 2000). First of all, note that there is an implicit assumption that Russia is a Stackelberg price leader vis-à-vis the competitive fringe. An alternative approach would be to have a Nash-Cournot equilibrium between Russia and the competitive fringe. Ulph and Folie (1980) compare the two approaches for the case of oil, and find that the Nash-Cournot approach has the undesirable property that it can lead to an unstable equilibrium in which the dominant firm's profits are lower than under perfect competition. In a slightly different (non-energy) setting, Deneckere and Kovenock (1992) show that in duopolistic price leadership games in which firms have capacity constraints, the smaller firm strictly prefers - under a relatively wide range of conditions to be a follower, as opposed to being the leader or making decisions simultaneously. These results support our assumption that Russia behaves as a Stackelberg leader vis-à-vis the competitive fringe. Secondly, the standard textbook approach mentions an alternative solution, in which a dominant firm with low costs can completely push the competitive fringe out of the market, by setting a price below the 'kink' in the residual demand curve. However, the calibration later in our paper shows that $c_{0}<c_{R}$, so we do not have to consider this alternative solution.
} 
the traditional solution of the 'dominant firm - competitive fringe' model: ${ }^{21}$

$$
q_{R, 1}=-\frac{1}{2 \beta d_{0}}\left[\left(\alpha+\beta q_{D}\right) d_{0}-\beta c_{0}-c_{R}\left(d_{0}-\beta\right)\right]
$$

\subsection{Stage 1: Storage investment decision}

Equations (10), (12) and (13) describe special cases in which, among others, $q_{S}=0$. In the complete derivation of the model, all these equations are a function of $q_{S}$, the storage capacity investment decision that Europe makes in Stage 1. Therefore, also $E[S]$ can be expressed as a function of a single decision variable $q_{S}$. In Stage 1, Europe chooses the amount of storage capacity investment $q_{S}$ that maximizes $E[S]$, obviously subject to the constraint $q_{S} \geq 0 .{ }^{22}$ Once $q_{S}$ is determined, $q_{R, 1}$ can be computed, followed by $q_{0}, p_{R, 1}, p_{0}, q_{R, 2}$ and $p_{R, 2}$, according to the equations above.

The existence of a unique pure-strategy equilibrium is guaranteed because our model consists of a set of sequential decisions, each of which is based on a quadratic (concave) pay-off function.

\section{NUMERICAL RESULTS}

The parameters of the model are calibrated on cost data and elasticities from the literature, the 2007 baseline for volume, and the average price 2003-2007. Annex C contains details on the choice of the parameters, while Annex E performs a sensitivity analysis on the elasticities.

\footnotetext{
${ }^{21}$ The resulting contract quantity $q_{R, 1}$ in the general case can be expressed analytically, but the result is long and not very insightful.

${ }^{22}$ The unconstrained optimal value of $q_{S}$ tends to $-\infty$ as $\delta \rightarrow 0^{+}$. Hence, for sufficiently small $\delta$ the constraint is always binding: $q_{S}=0$. Under certain conditions, the constraint is binding across the entire interval $\delta \in[0,1]$. Under other conditions, there is a threshold $\delta=\delta_{S}$ above which the constraint is not binding. In the latter case the optimal $q_{S}$ can be expressed analytically. However, the threshold $\delta_{S}$ itself cannot be calculated analytically, since it is the solution of a polynomial of order 7 in $\delta$. Section 4 numerically computes the threshold levels $\delta_{S}$ under various conditions.
} 


\subsection{Effect of default probability $\delta$ on long-term gas import contracts and pay-offs}

The top half of Figure 6 shows how quantities and prices vary as $\delta$, the probability of Russian 'default', goes from 0 to 1 . The graph also shows the discount $\Delta p$ of long-term gas import contracts offered by Russia compared to contracts offered by the competitive fringe ( $\Delta p=$ $\left.p_{0}-p_{R, 1}\right)$.

For $\delta=0$, there is no risk and there is obviously no price difference between the contract with Russia and the contracts with the competitive fringe. The simulation shows that in this case, Europe buys $q_{R, 1}=135 \mathrm{bcm}$ per year from Russia and $q_{0}=94 \mathrm{bcm}$ per year from the other suppliers. This is not too far from the actual data in 2007 as cited by BP (2006-2008), which mentions $120 \mathrm{bcm}$ per year from Russia and $95 \mathrm{bcm}$ per year from other non-European import suppliers. Indeed, until recently, Russia was considered a reliable supplier, and so it is not surprising that the currently observed market quantities correspond to the case $\delta=0$.

For $\delta>0$ Russia becomes unreliable. When Russia 'defaults', it delivers only an annualized amount $q_{R, 2}$ instead of $q_{R, 1}$, at a higher price $p_{R, 2}$ instead of the originally agreed long-term gas import contract price $p_{R, 1}$. Panel (a) of Figure 6 shows that the quantity withheld would be around $40 \%$ and panel (b) shows that the resulting price increase would be around $40 \%$ as well. Although substantial, such a price increase is only a 2-sigma event over 3 trading days at gas hubs such as NBP (National Balancing Point, in the UK) when considering a typical daily volatility of $10 \% .^{23}$

As $\delta$ increases, Europe increases its volume $q_{0}$ of long-term gas import contracts with the competitive fringe, at a slowly increasing contract price $p_{0}$. Meanwhile, Europe procures a smaller volume $q_{R, 1}$ with long-term contracts from Russia, even though Russia is obliged to give an increasing discount $\Delta p$ to 'compensate' the risk for Europe. It is obvious why Russia would want to give the discount: as $\delta$ increases, there is a higher chance that Russia can charge

\footnotetext{
${ }^{23}$ In fact over the period 2003-2007 there have been 13 instances of (day-ahead) spot price increases of $40 \%$ or more between the closing prices of two consecutive trading days. However, we need to mention that only a very small share of gas volumes is traded on the gas hub spot markets, and liquidity is particularly low on the days with large swings.
} 
Figure 6: Base scenario: Relation between $\delta$ (horizontal axis) and quantities, prices, consumer surplus and supplier profits (vertical axis)*

(a) Quantities

(bcm)

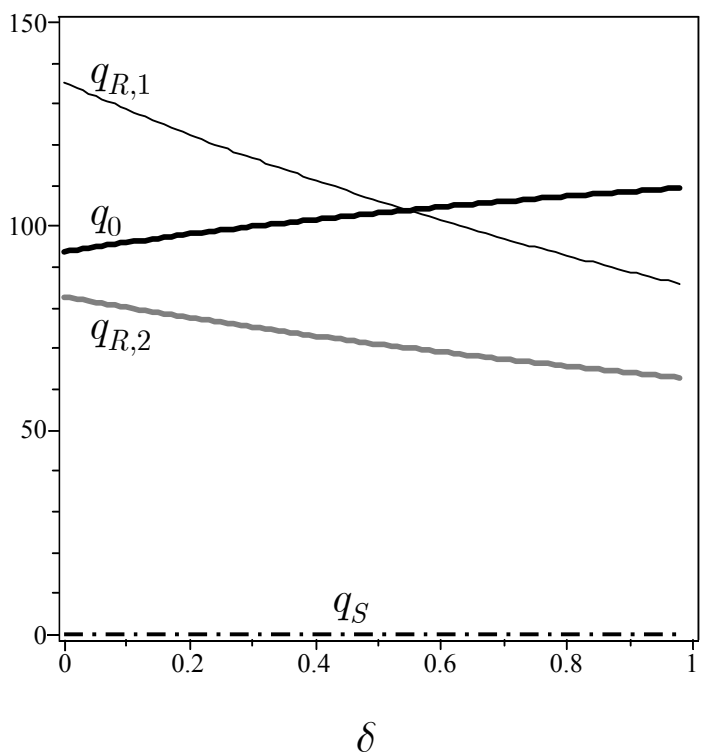

(c) European surplus

(EUR Billions)

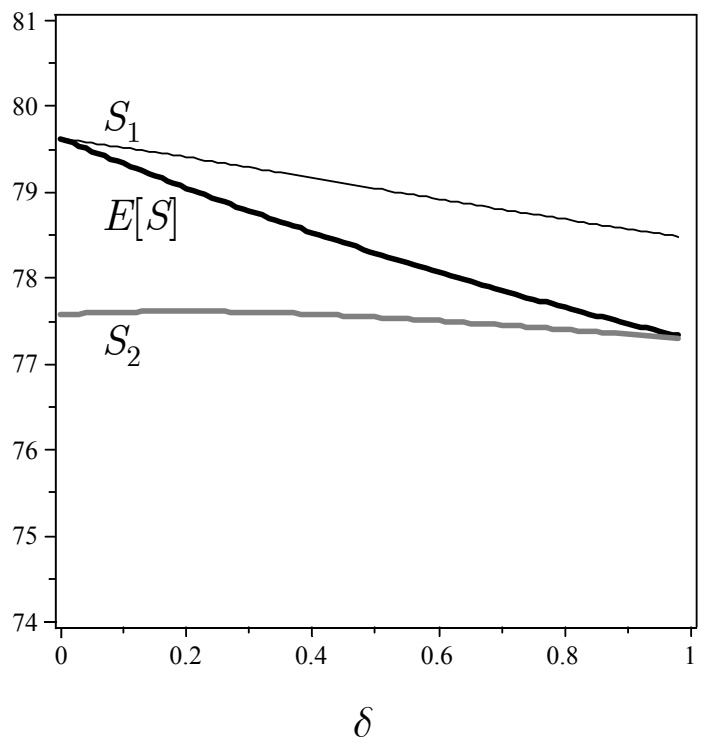

(b) Prices

(EUR / tcm)

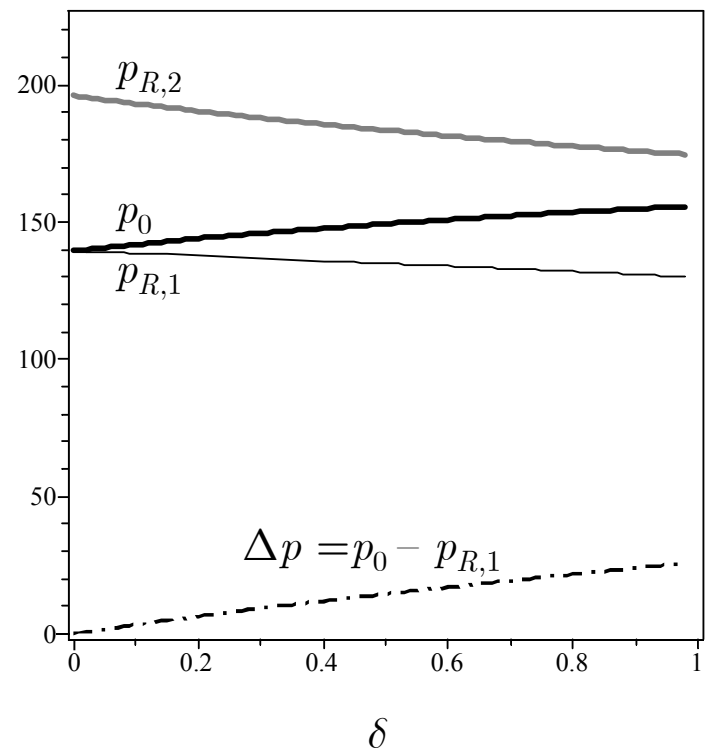

(d) Supplier profits (EUR Billions)

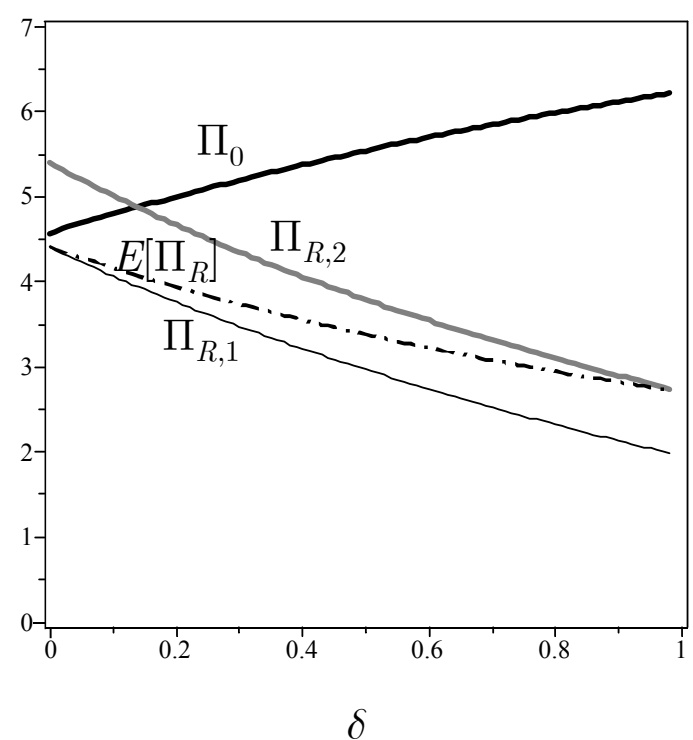

${ }^{*}$ Note that $q_{R, 2}$ is an 'annualized' amount in the sense of Footnote 16, which means that $q_{R, 2}$ is extrapolated as if the crisis lasts the entire year instead of 4 months. On the other hand, $S_{2}$ and $\Pi_{R, 2}$ do take into account that the crisis is limited to 4 months: they contain 4 months of crisis plus 8 months of non-crisis. 
the monopoly price $p_{R, 2}$ in Stage 3 (by supplying only a quantity $q_{R, 2}$ of gas). By giving a discount $\Delta p$, Russia can induce Europe to sign the long-term gas import contracts $q_{R, 1}$ (despite the unreliability), which puts Europe in a vulnerable situation. For example, for $\delta=20 \%$, the Russian contractual discount is $6.3 \mathrm{EUR} / \mathrm{tcm}$ or roughly $4.5 \%$ of the price, which is consistent with the approximative equation (11) which predicts a discount of $4.4 \%$. Despite the discount, Russia loses market share as $\delta$ increases and for $\delta>57 \%$ supply from the competitive fringe outstrips Russian supply. Clearly, Europe tries to make itself less dependent on Russia and therefore less vulnerable in the event of Russian withholding.

Panels (c) and (d) of Figure 6 show the effect on European surplus and on suppliers' profits, respectively. Recall that $S_{1}$ is the European surplus in Case 1 (Russia complies with long-term contracts) while $S_{2}$ is the European surplus in Case 2 (Russia defaults). $E[S]$ is the expected value of the European surplus. For $\delta=0$ and $\delta=1$, we obviously find $E[S]=S_{1}$ and $E[S]=S_{2}$, respectively. As $\delta$ increases, $E[S]$ decreases: despite the Russian discount and shifting supply mix, Russian unreliability causes a loss of expected European surplus. Panel (d) shows Russia's profits in Case $1\left(\Pi_{R, 1}\right)$, Case $2\left(\Pi_{R, 2}\right)$ and the expected value $E\left[\Pi_{R}\right]$, as well as the profits $\Pi_{0}$ obtained by the competitive fringe. Clearly, Russia's expected profits decrease monotonically with increasing $\delta$ : the negative impact of the Russian contract discount and loss of Russian market share is not sufficiently counterbalanced by Russia's increased likelihood of benefiting from a crisis. The only party gaining from increased unreliability is the competitive fringe. The competitive fringe profits $\Pi_{0}$ increase with increasing $\delta$, because increased Russian unreliability allows them to sell a larger volume at a higher price.

The most important observation is that both Russia and Europe suffer when $\delta$ increases. Although $\delta$ is exogenous in our model, the results show that it would be attractive for both Europe and Russia to invest in a more reliable relationship, i.e. lower $\delta$. 


\subsection{Conditions for strategic gas storage capacity investment $q_{S}>0$}

In the simulations of Figure 6, the value of $q_{S}$ is always 0 , meaning that it is never interesting for Europe to build any strategic gas storage capacity whatever the value of $\delta$. The annual cost of storage capacity, $c_{S}=50$ EUR per tcm per year, is too high compared to the potential gains. Figure 7 repeats the simulations with $c_{S}=15$ EUR per tcm per year. ${ }^{24}$ The result

Figure 7: Scenario with reduced storage costs: Relation between $\delta$ (horizontal axis) and quantities and prices (vertical axis)

(a) Quantities

(bcm)

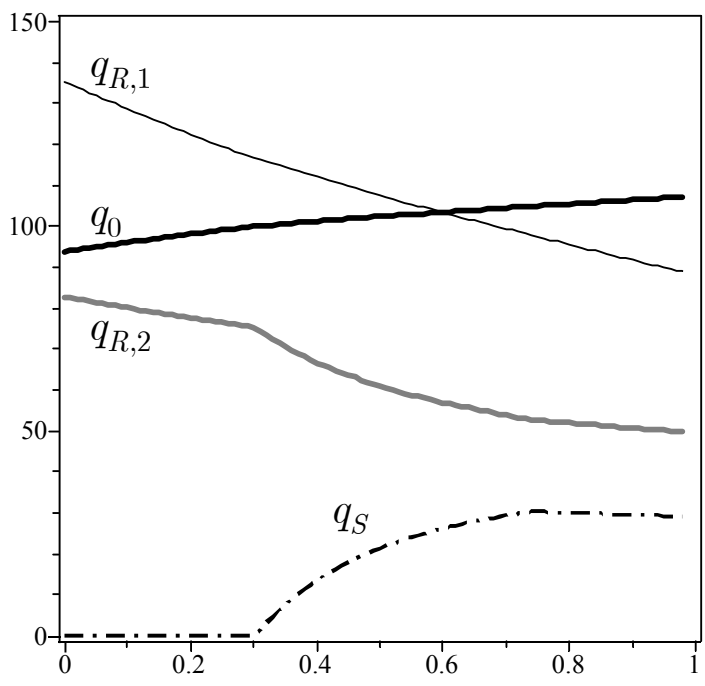

$\delta$ (b) Prices

(EUR / tcm)

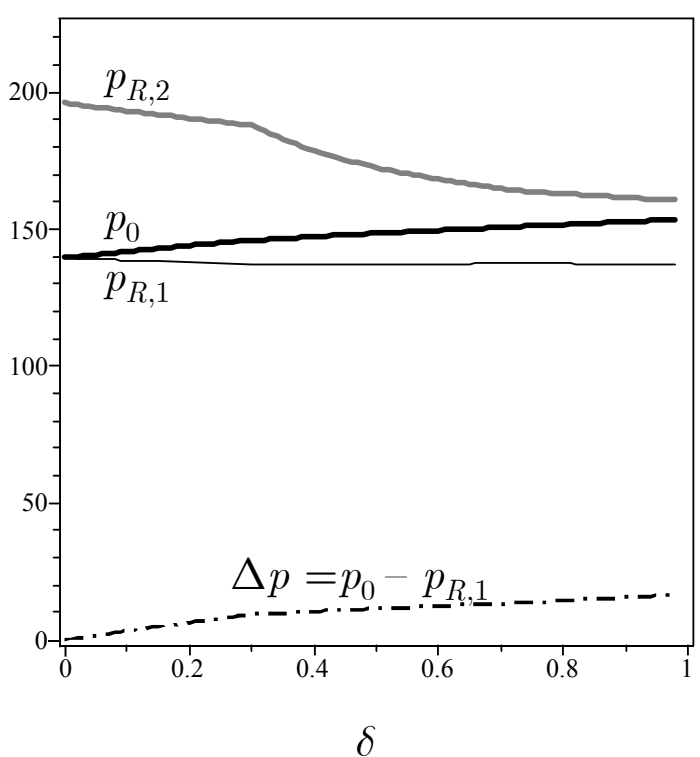

is identical to Figure 6 for $\delta<30 \%$. For $\delta \geq 30 \%$, Russian unreliability is high enough to make investments in strategic gas storage capacity $q_{S}$ competitive. As of that point, $p_{R, 2}$ (Russia's potential 'monopoly price') drops significantly. As a result, Russia's market share loss compared to the competitive fringe slows down slightly, while its discount $\Delta p$ flattens out.

\footnotetext{
${ }^{24}$ In particular, if the storage site could be set up so that it can be used for seasonal arbitrage while the cushion gas serves as strategic storage, the cost of strategic storage would be significantly reduced. Typical ratios of total gas (working gas plus cushion gas) to working gas are 3-4 for aquifers and depleted reservoirs, hence our choice $c_{S}=15$ instead of 50 EUR per tcm per year.
} 
Besides lower storage capacity costs $c_{S}$, another factor that can encourage investments in strategic gas storage capacity, is risk aversion. Annex D explains how our model can take into account European risk aversion, as measured by $\theta$, the coefficient of relative risk aversion. Typical values of $\theta$ are 2 to 4 for financial assets and 10 to 15 when real assets are also included (Palsson, 1996). $\theta=0$ corresponds to the risk-neutral case which we have been studying in this paper so far. Figure 8 covers different values of $\theta$. For each value of $\theta$, the graph contains a curve (as a function of $\delta$ ) that shows the maximum value of $c_{S}$ for which $q_{S}>0$. There is

Figure 8: Relation between $\delta$ (horizontal axis) and maximum value of $c_{S}$ (in EUR per tcm per year) for which $q_{S}>0$ (vertical axis), for different levels of risk aversion $\theta$

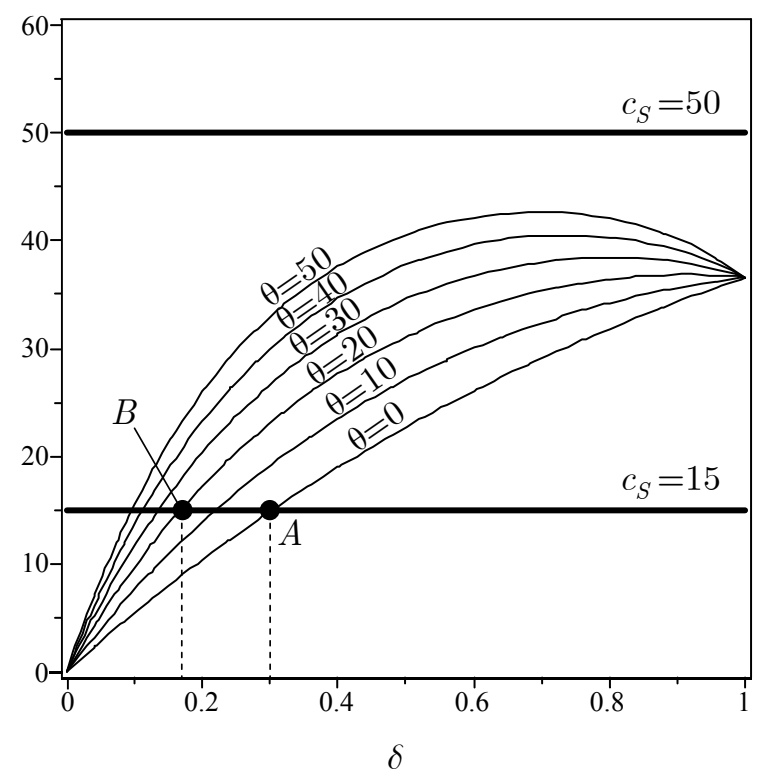

storage investment $q_{S}>0$ in the region of the $\left(\delta, c_{S}\right)$ space below each curve. One can see that for $\theta=0$ and $c_{S}=15$ EUR per tcm per year, the storage option becomes interesting for $\delta \geq 30 \%$ (point $A$ ), which is obviously identical to what has been observed in Figure 7. If $\theta$ goes up to 20, then the threshold level comes down to $\delta=17 \%$ (point $B$ ). However, for $c_{S}=50$ EUR per tcm per year, storage remains unattractive, unless $\theta \gg 50$, which is highly unrealistic. 


\section{CONCLUSIONS}

The first research question of this paper is how Russian unreliability may impact the European gas market and how this affects European gas import decisions. Our numerical simulations show that it is not optimal for Russia to cut gas supplies to Europe completely during a crisis: rather, one can expect Russia to reduce its gas supplies by roughly $40 \%$, thereby temporarily increasing gas prices by roughly $40 \%$. More importantly, the analysis shows that not only Europe but also Russia suffers when Russia's probability of default $\delta$ increases, due to erosion of its price and market share. The second research question of this paper is to what extent Europe should invest in strategic gas storage capacity to mitigate the effects of possible supply withholding by Russia. We find that strategic storage capacity is attractive for Europe only if Russian unreliability is high ( $\delta$ of more than $30 \%$ ) and storage capacity costs are reduced by a factor 3 to 4 compared to typical current cost levels. The threshold of $30 \%$ default probability is lowered when Europe is assumed to be risk averse.

The results of this paper are obtained using a partial equilibrium model of the market for long-term gas import contracts, with differentiated competition between one potentially unreliable 'dominant firm' (Russia) and a reliable 'competitive fringe' of other non-European import suppliers. Future research could examine the impact of the other suppliers becoming unreliable as well. Another possible extension is to turn our model into a repeated game. In such a game, $\delta$ could become endogenous as part of a mixed Russian strategy. Finally, the topic of this paper could be placed in a broader comparison of policy measures (import taxes, rationing, interruptible consumer contracts, etc.) that can be used to address gas import challenges.

\section{References}

BAFA (2009). Monatliche Erdgasbilanz und Entwicklung der Grenzübergangspreise, ausgewählte Statistiken zur Entwicklung des deutschen Gasmarktes, Bundesministerium für Wirtschaft und Technologie - Bundesamt für Wirtschaft und Ausfuhrkontrolle, http://www.bmwi.de/BMWi/Navigation/Energie/Energiestatistiken/ gasstatistiken.html, last consulted in June 2009. 
Boots, M., F. Rijkers and B. Hobbs (2004). "Trading in the Downstream European Gas Market: A Successive Oligopoly Approach", The Energy Journal 25(3): 73-102.

Boucher, J., T. Hefting and Y. Smeers (1987). "Economic Analysis of Natural Gas Contracts", in Golombek et al. (1987).

BP (2006/2007/2008). Statistical Review of World Energy June 2006/2007/2008, London, BP p.l.c.

Carlton, D., and J. Perloff (2000). Modern Industrial Organization, Third Edition, Reading, Massachusetts, Addison-Wesley.

Dahl, C. (1993). A Survey of Energy Demand Elasticities in Support of the Development of the NEMS, Paper prepared for United States Department of Energy, Contract De-AP01-93EI23499.

Deneckere, R., and D. Kovenock (1992). "Price Leadership", The Review of Economic Studies 59: 143-162.

European Commission (2007). An Energy Policy for Europe, Communication to the European Council and the European Parliament.

Gaudet, G. and M. Moreaux (1990). "Price versus Quantity Rules in Dynamic Competition: The Case of Nonrenewable Natural Resources”, International Economic Review 31(3): 639-650.

Golombek, R., M. Hoel and J. Vislie (eds.) (1987). Natural Gas Markets and Contracts, North Holland, Elsevier Science Publishers.

Golombek, R. and E. Gjelsvik (1995). "Effects of Liberalizing the Natural Gas Markets in Western Europe", The Energy Journal 16(1).

Golombek, R., E. Gjelsvik and K. Rosendahl (1998). "Increased Competition on the Supply Side of the Western European Natural Gas Market”, The Energy Journal 19(3): 1-18.

Grais, W. and K. Zheng (1996). "Strategic Interdependence in European East-West Gas Trade: A Hierarchical Stackelberg Game Approach”, The Energy Journal 17(3): 61-84.

Hartley, P. and K. Medlock III (2009). "Potential Futures for Russian Natural Gas Exports", The Energy Journal 30(Special Issue): 73-95.

von Hirschhausen, C., B. Meinhart and F. Pavel (2005). "Transporting Russian Gas to Western Europe - A Simulation Analysis", The Energy Journal 26(2): 49-68.

Holz F., C. von Hirschhausen and C. Kemfert (2008). "A strategic model of European gas supply (GASMOD)", Energy Economics 30: 766-788.

Hubert, F. and S. Ikonnikova (2004). Holdup, Multilateral Bargaining, and Strategic Investment: The Eurasian Supply Chain for Natural Gas, Working paper Humboldt University Berlin.

Ikonnikova, S. and G. Zwart (2009). "Strengthening buyer power on the EU gas market: Import caps and supply diversification”, Presentation at KULeuven Energy Institute Seminar, May 2009.

International Energy Agency (2008). World Energy Outlook 2008, Paris, OECD/IEA. 
Lise W., B. Hobbs and F. van Oostvoorn (2008). "Natural gas corridors between the EU and its main suppliers: Simulation results with the dynamic GASTALE model”, Energy Policy 36: 1890-1906.

Mas-Colell A., M. Whinston and J. Green (1995). Microeconomic theory, New York, Oxford University Press.

Mathiesen, L., K. Roland and K. Thonstad (1987). "The European natural gas market: degrees of market power on the selling side", in Golombek et al. (1987).

Mulder, M. and G. Zwart (2006). Government involvement in liberalised gas markets, CPB document No 110, Centraal Planbureau, Netherlands.

Neuhoff, K. and C. von Hirschhausen (2005). Long-term contracts vs. short-term trade of natural gas -A European perspective, Working paper University of Cambridge.

Nordhaus, W. (1974). "The 1974 Report of the President's Council of Economic Advisers: Energy in the Economic Report”, American Economic Review 64(4): 558-565.

OME - Observatoire Méditerranéen de l'Energie (2002). Assessment of internal and external gas supply options for the EU, evaluation of the supply costs of new natural gas supply projects to the EU and an investigation of related financial requirements and tools, Study for the European Commission.

Palsson, A.-M. (1996). "Does the degree of relative risk aversion vary with household characteristics?", Journal of Economic Psychology, 17: 771-787.

Peltzman, S. (1976). "Toward a more general theory of regulation", Journal of Law and Economics, 19:211-240.

Singh, N. and X. Vives (1984). "Price and quantity competition in a differentiated duopoly", Rand Journal of Economics 15(4): 546-554.

Stigler, G. (1971). "The theory of economic regulation", Bell Journal of Economics and Management Science 2:3-21.

Ulph, A. and G. Folie (1980). "Economic Implications of Stackelberg and Nash-Cournot Equilibria", Journal of Economics 40(3-4): 343-354.

Various specialized and general press sources (2006). Several articles from January to August 2006, and January 2009 from International Herald Tribune (Paris, The New York Times Company), De Tijd (Brussels, Uitgeversbedrijf Tijd NV).

\section{A Annex: Optimal quantity and price for Russia in case of default}

This annex explains equation (7). Russia's annualized profits during the crisis are:

$$
\Pi_{R, \text { crisis }}=\left(p_{R, 2}-c_{R}\right) q_{R, 2}
$$


where $p_{R, 2}$ and $q_{R, 2}$ follow the short-run demand curve (2) around the point $\left(q_{D}+q_{0}+q_{R, 1} ; p^{*}\right)$ :

$$
p_{R, 2}=p_{S R}\left(q_{D}+q_{0}+q_{S}+q_{R, 2}\right) \quad \text { with } \quad p_{S R}(q)=p^{*}+\beta_{S R} \cdot\left(q-q_{R, 1}-q_{0}-q_{D}\right)
$$

To determine the optimal $q_{R, 2}$ (and consequently, the optimal $p_{R, 2}$ ) the derivative of (14) is used:

$$
\begin{aligned}
\frac{d \Pi_{R, \text { crisis }}}{d q_{R, 2}} & =\frac{\partial \Pi_{R, \text { crisis }}}{\partial q_{R, 2}}+\frac{\partial \Pi_{R, \text { crisis }}}{\partial p_{R, 2}} \cdot \frac{d p_{R, 2}}{d q_{R, 2}} \\
& =\left[p_{S R}\left(q_{D}+q_{0}+q_{S}+q_{R, 2}\right)-c_{R}\right]+\left[q_{R, 2} \cdot p_{S R}^{\prime}\left(q_{D}+q_{0}+q_{S}+q_{R, 2}\right)\right](16)
\end{aligned}
$$

Setting (16) $=0$ and solving together with (15), yields the monopoly quantity and price shown in equations (7). Strictly speaking, the Kuhn-Tucker conditions for constrained optimization with constraint $q_{R, 2} \geq 0$ should be used. This constraint is ignored in the analytical presentation of Section 3, but in the numerical simulations of Section 4 it is taken into account, not only for $q_{R, 2}$, but also for $q_{0}, q_{R, 1}$ and $q_{S}$. Except for $q_{S}$, the constraint is never binding. Note that (7) is the well-known textbook expression for monopoly pricing with linear demand and constant marginal cost.

\section{B Annex: Russian discount $\Delta p=p_{0}-p_{R, 1}$}

This annex explains equation (11). We develop a first-order approximation for $\Delta p$ around $\delta=0$. In first order, the inverse demand functions (10) reduce to:

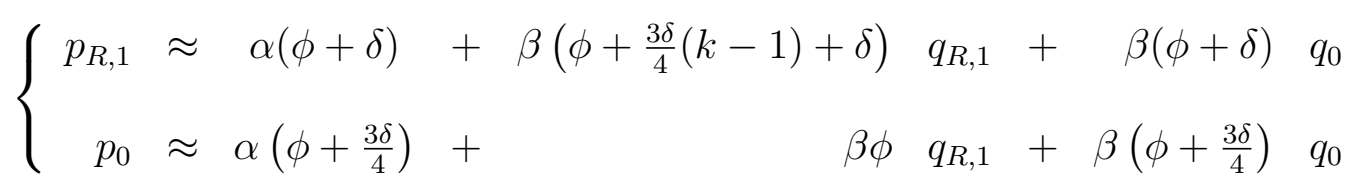

using the fact that $\phi /(1-\delta) \approx \phi+\delta$ in first order. Subtracting the first equation from the second, we obtain:

$$
\Delta p \approx \frac{\delta}{4}\left[-3 \beta k q_{R, 1}-\alpha-\beta q_{R, 1}-\beta q_{0}\right]
$$

The inverse demand functions (10) describe the special case in which $\tau=1, q_{S}=q_{D}=0$ and $c_{R}=0$. When we redo the exercise with those parameters included, equation (18) modifies 
only slightly:25

$$
\Delta p \approx \frac{\delta \tau}{4}\left[-3 \beta k q_{R, 1}-\alpha-\beta q_{R, 1}-\beta q_{0}-\beta q_{D}+c_{R}\right]
$$

which can be further simplified, using $p^{*}=\alpha+\beta \cdot\left(q_{D}+q_{0}+q_{R, 1}\right)$ and the short-run equivalent of equation (24) - assuming $q^{*} \approx q_{c a l}$ and $p^{*} \approx p_{\text {cal }}$. We obtain:

$$
\begin{aligned}
\Delta p & \approx \frac{\delta \tau}{4}\left[-3 \beta_{S R} q_{R, 1}-p^{*}+c_{R}\right] \\
& \approx \frac{\delta \tau}{4}\left[3\left(\frac{1}{\left|e_{S R}\right|} \frac{p^{*}}{q^{*}}\right) q_{R, 1}-\left(p^{*}-c_{R}\right)\right]
\end{aligned}
$$

After dividing by $p^{*}$ we obtain: ${ }^{26}$

$$
\frac{\Delta p}{p^{*}} \approx \frac{\delta \tau}{4}\left[\frac{3}{\left|e_{S R}\right|}\left(\frac{q_{R, 1}}{q^{*}}\right)-\left(1-\frac{c_{R}}{p^{*}}\right)\right]
$$

Since we typically have:

$$
\frac{3}{\left|e_{S R}\right|}\left(\frac{q_{R, 1}}{q^{*}}\right) \gg 1-\frac{c_{R}}{p^{*}}
$$

equation (22) can be further approximated by equation (11). ${ }^{27}$

\section{Annex: Calibration of the model parameters for the nu- merical simulations}

This section describes the numerical assumptions for the parameters used in our model, which are based on estimates from the literature.

Demand. The parameters $\alpha, \beta$ and $\beta_{S R}$ are determined using elasticities from the literature, the 2007 baseline for volume, and the average price 2003-2007. $\beta$ can be easily derived from

\footnotetext{
${ }^{25}$ Since Section 3.3 shows that $q_{S}=0$ for small enough values of $\delta$, we keep $q_{S}=0$ in the derivation of equation (19).

${ }^{26}$ Note that Russia's discount decreases when its rent margin $\left(1-c_{R} / p^{*}\right)$ increases. Naively, one might think that Russia's discount should increase in case of a higher rent margin, since a higher rent margin offers more financial room for discounting. However, a higher rent margin provides Russia with an incentive to withhold less in the event of a default, thus leading to a lower discount on the long-term contract price.

${ }^{27}$ With the calibration parameters used in the rest of the paper, the left-hand side of equation (23) is roughly 10 times larger than the right-hand side.
} 
a calibration point $\left(p_{\text {cal }}, q_{\text {cal }}\right)$ and an elasticity value $e$ :

$$
\beta=\frac{1}{e} \frac{p_{c a l}}{q_{c a l}}
$$

Long-run price elasticity of demand is taken equal to -0.93, following Golombek et al. (1998). Short-run price elasticity of demand is determined based on the very comprehensive literature survey of Dahl (1993). In Dahl (1993), the average short-run elasticity over the 15 studies that compute both short-run and long-run elasticities is $-0.27 .{ }^{28}$ In case this value seems large (in absolute terms), one should consider that we are ignoring any elasticity of European domestic supply: $q_{D}$ is exogenous and fixed. A non-zero elasticity of domestic supply would have the same effect as increasing (in absolute terms) the elasticity of demand. In addition, our model allows Russia to withhold supplies for 4 months at a time. This means that our short-run price elasticity of demand relates to a time frame of a few months, which makes the value of -0.27 seem reasonable. For the sake of safety, Annex E performs a sensitivity analysis on the elasticities.

According to BP (2006-2008), total European gas consumption in 2007 was $q_{c a l}=494$ bcm per year. The average German border price as registered by the German government $\left(\right.$ BAFA, 2009) was $p_{c a l}=144$ EUR per tcm over the period 2003-2007. Based on these numbers and the above-mentioned elasticities, the resulting $\beta, \beta_{S R}$ and, finally, $\alpha$ can be determined.

Costs. Total per-unit production and transportation costs are based on OME (2002), which shows costs curves for additional volumes of gas supply to the EU in $2010 .{ }^{29}$ For Russia, marginal costs are assumed constant ( $c_{R}$, see Section 2.2). ${ }^{30}$ According to OME (2002), the long-run marginal cost for production in the Nadym-Pur-Taz region with transport through

\footnotetext{
${ }^{28}$ Note that the average long-run elasticity of the same 15 studies was -0.99 , which is in line with the -0.93 from Golombek et al. (1998).

${ }^{29}$ Supply to the EU-15 is used because this is the most realistic estimate of the cost of supply to an 'average' country in Europe. Using data for EU-27 would understate the costs for Russia.

${ }^{30}$ Our assumptions about marginal production costs are a slightly simplified version of Boots et al. (2004) and Golombek et al. (1995, 1998), who model marginal production costs as:

$$
M C_{\text {production }}=a+b q+c \ln (1-q / Q)
$$


Ukraine (a combination which represents a very large share of current Russian exports) is $\$ 2.8 / \mathrm{MMBtu}$. The long-run marginal cost for production on the Yamal peninsula with transport through Belarus (a combination which represents large future potential for Russian exports) is also $\$ 2.8 / \mathrm{MMBtu}$. We therefore choose $c_{R}=\$ 2.8 / \mathrm{MMBtu}$, or $107 \mathrm{EUR} / \mathrm{tcm} .{ }^{31}$ For the other suppliers, we assume that marginal costs are linearly increasing $\left(c_{0}+d_{0} q_{0}\right.$, see Section 2.2). For $c_{0}$, we choose the cheapest source of gas imports to the EU-15 according to OME (2002): Algerian gas imported via the MedGaz pipeline at $\$ 1.1 / \mathrm{MMBtu}$. So $c_{0}=42$ EUR/tcm. The slope $d_{0}$ of the marginal cost curve is determined based on the slope of the cost curve for additional gas imports into the EU-15 on p. 14 of the OME (2002) report, excluding domestic European and Russian supplies. The cost curve for additional gas supplies starts at $\$ 1.1 / \mathrm{MMBtu}$ with Algerian gas, and climbs up to $\$ 3.0 / \mathrm{MMBtu}$ (Qatar LNG) to reach an additional volume of $70 \mathrm{bcm}$ per year. We therefore choose $d_{0}=(\$ 1.9 / \mathrm{MMBtu}) / 70 \mathrm{bcm}=$ $1.04 \mathrm{EUR} / \mathrm{tcm} / \mathrm{bcm}$. The annual gas storage capacity costs $c_{S}$ are taken at the lower end of the range 50-70 EUR per tcm per year, mentioned by Mulder and Zwart (2006).

\section{Annex: Modeling European risk aversion}

Equation (3) assumes risk-neutrality: Europe maximizes the expected value of European surplus $S$. The most straightforward way to introduce risk aversion is to assume instead that Europe maximizes the expected value of a concave transformation of European surplus. A theoretical justification for this transformation is to model European decision-making using the Stigler-Peltzman model ${ }^{32}$ and assume that Europe maximizes a political support function

where $q$ is production and $Q$ is capacity (the third term makes production costs go up to infinity as soon as capacity is reached). The constants $a, b, c$ and $Q$ are determined for each supplier country separately. The exact values of $a, b, c$ and $Q$ are listed in Golombek et al. (1995), and are the same in the three studies Boots et al. (2004) and Golombek et al. (1995, 1998). For Russia however, $b$ is 0 , which is in line with the assumption of constant marginal cost used in this paper. Compared to Boots et al. (2004) and Golombek et al. $(1995,1998)$, our main assumptions are that (i) we leave out the non-linear capacity term $c \ln (1-q / Q)$ for both Russia and the other suppliers (to keep our model analytically solvable), and (ii) we aggregate the production of the other suppliers and assume a linear marginal cost curve for the total.

${ }^{31}$ USD/EUR conversions are done at the average exchange rate for the year 2002 in which the OME estimates were made ( $1 \mathrm{USD}=1.06 \mathrm{EUR})$.

${ }^{32}$ See Stigler (1971) and Peltzman (1976). 
$M:$

$$
M=M\left(C S, \Pi_{D},-G\right)
$$

instead of maximizing just $S$ as in equation (3). Assuming that different constituencies are treated identically, we can simplify the expression for $M$ :

$$
M=f(S) \quad \text { with } \quad S=C S+\Pi_{D}-G
$$

Following Peltzman (1976), we have $f^{\prime}>0$ and $f^{\prime \prime}<0$. If Europe's objective is to maximize the expected value of $M$, then the concavity of $f$ leads to risk averse behavior. ${ }^{33}$ To make the degree of risk aversion explicit, we choose a particular functional form for $f(\cdot)$, namely a function that yields constant relative risk aversion (CRRA):

$$
f(x)=u_{\theta}(x)=\frac{x^{1-\theta}}{1-\theta}
$$

$\theta$ is the coefficient of relative risk aversion. ${ }^{34}$

To determine the European inverse demand functions for long-term gas import contracts (Section 3.2), we need to maximize $E[M]=E[f(S)]$ instead of $E[S]$. Since $f^{\prime}>0$, the maximization of $E[f(S)]$ is equivalent to the maximization of $C=f^{-1}(E[f(S)])$. Let us now define $\epsilon=S_{1}-S_{2}=\tau \Delta S$, i.e. the potential 'downside' of the deal with Russia. We need to maximize:

$$
\begin{aligned}
C & =u_{\theta}^{-1}\left((1-\delta) u_{\theta}\left(S_{1}\right)+\delta u_{\theta}\left(S_{2}\right)\right) \\
& =u_{\theta}^{-1}\left((1-\delta) u_{\theta}\left(S_{1}\right)+\delta u_{\theta}\left(S_{1}-\epsilon\right)\right) \\
& \approx S_{1}-\delta \epsilon-\frac{1}{2} \delta(1-\delta) \theta \frac{\epsilon^{2}}{S_{1}}+\text { higher-order terms in } \theta \text { and } \epsilon
\end{aligned}
$$

in which the last step results from a Taylor expansion around $\theta=0$ and $\epsilon=0$. By defining $\sigma$ :

$$
\sigma=\delta+\frac{1}{2} \delta(1-\delta) \theta A \quad \text { with } \quad A=\frac{S_{1}-S_{2}}{S_{1}}
$$

\footnotetext{
${ }^{33}$ In the true sense of the political support function, this would only model the risk aversion of the politicians. However, we shall assume that risk aversion of consumers and domestic producers is also included in $f$.

${ }^{34}$ The precise level of risk aversion $\theta$ is a parameter to the simulations. Section 4.2 contains simulations for different values of $\theta$.
} 
we can rewrite equation (29) as:

$$
C \approx S_{1}-\sigma \epsilon=S_{1}-\sigma \tau \Delta S=(1-\sigma) S_{1}+\sigma S_{2}
$$

Equation (31) is completely equivalent to equation (9) but with $\delta$ replaced by $\sigma$. The analytical results of Section 3 therefore remain valid for a risk averse Europe, provided we replace $\delta$ by $\sigma$ in equations modeling Europe's decisions. This approach has the advantage of having a very intuitive interpretation: in equation (31), Europe 'perceives' a Russian default probability $\sigma$, which is different from the 'real' default probability $\delta$. Europe's risk aversion is thus modeled as a higher perceived default probability. ${ }^{35}$ For the cases $\delta=0$ and $\delta=1$, there is no uncertainty, so $\sigma=\delta$. The more uncertainty (i.e. the closer to $\delta=0.5$ ), the larger the difference between $\sigma$ and $\delta$.

\section{E Annex: Sensitivity analysis on elasticities}

The analyses in Section 4 assume that long-run price elasticity of European demand for imported gas is -0.93 , and that the short-run elasticity is -0.27 . In other words, the ratio $k$ between long-run and short-run elasticities is $3.4\left(k=e / e_{S R}=\beta_{S R} / \beta\right)$. The empirical evidence on this ratio $k$, however, is scattered. Neuhoff and Hirschhausen (2005) report $k$ values of 4 to 5 for industrial demand, and 5 up to 10 for residential and commercial demand. In this section we shall briefly review how the results of Section 4.1 change when we double $k$ from 3.4 to 6.8 .

First, let us double $k$ by reducing the short-run elasticity to half its original value, i.e. we set $e_{S R}=-0.14$ instead of -0.27 . The slope of the short-run demand curve $\beta_{S R}$ becomes twice as steep. We keep the long-run elasticity $e$ of gas demand constant, meaning that $\beta$

\footnotetext{
${ }^{35}$ The caveat is that $\sigma$ is actually not a constant, but depends on $A$, which is the proportional 'deviation' between $S_{1}$ and $S_{2}$. However, in addition to the approximations already made in the derivation of equation (31), $\sigma$ is treated as a constant in subsequent analyses. $\sigma$ therefore changes with $\delta$ as defined in equation (30), but does not depend on $S_{1}$ and $S_{2}$, because a fixed $A$ is taken. The value of $A$ is chosen to be 0.05 in the numerical simulations. This is about twice the value observed in Figure 6 (Panel (c)) in order to take into account the fact that the absolute value of European surplus is probably lower due to the costs of domestic production, which are ignored in the computation of $E[S]$.
} 
Figure 9: Scenario with halved short-run elasticity: Relation between $\delta$ (horizontal axis) and quantities and prices (vertical axis)

(a) Quantities

(bcm)

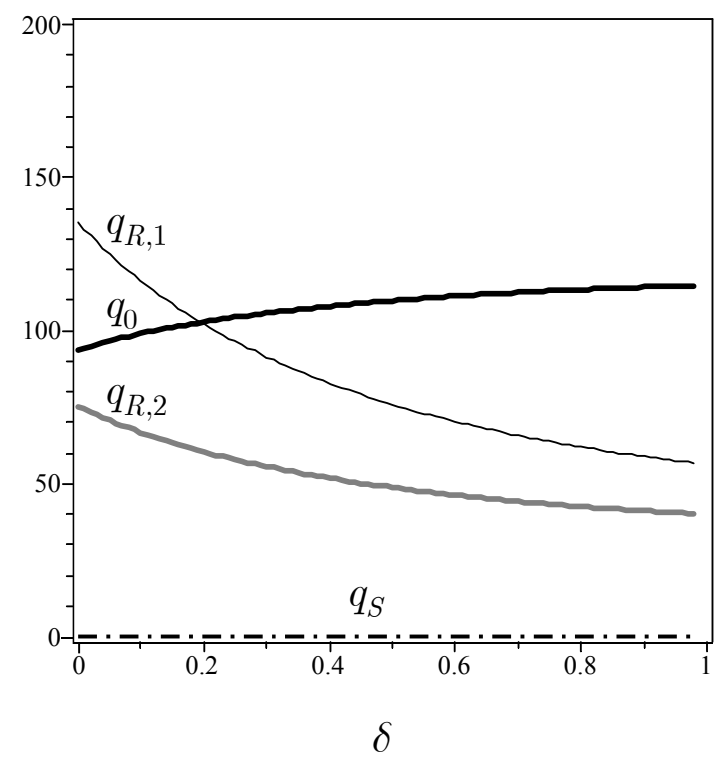

(b) Prices

(EUR / tcm)

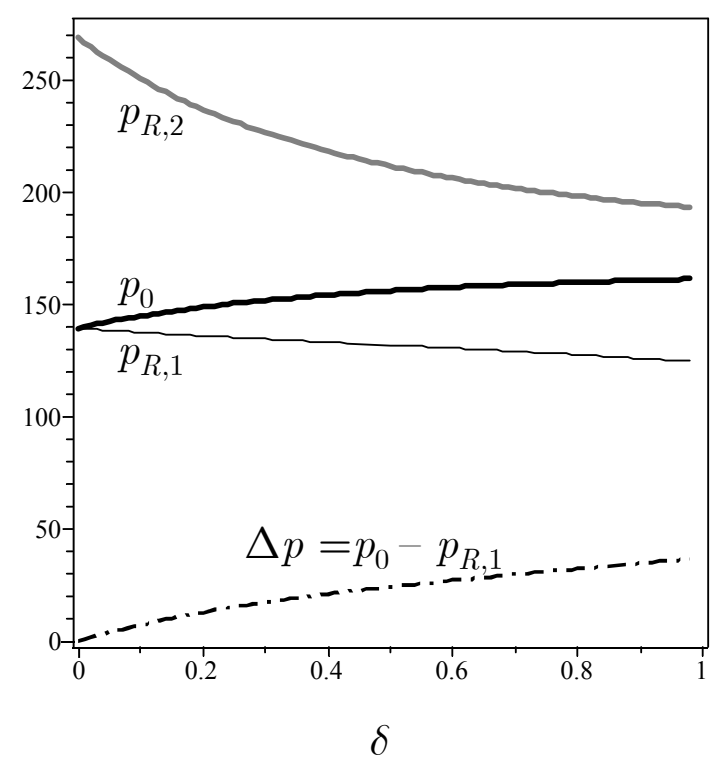

Figure 10: Scenario with double long-run elasticity: Relation between $\delta$ (horizontal axis) and quantities and prices (vertical axis)

(a) Quantities

(bcm)

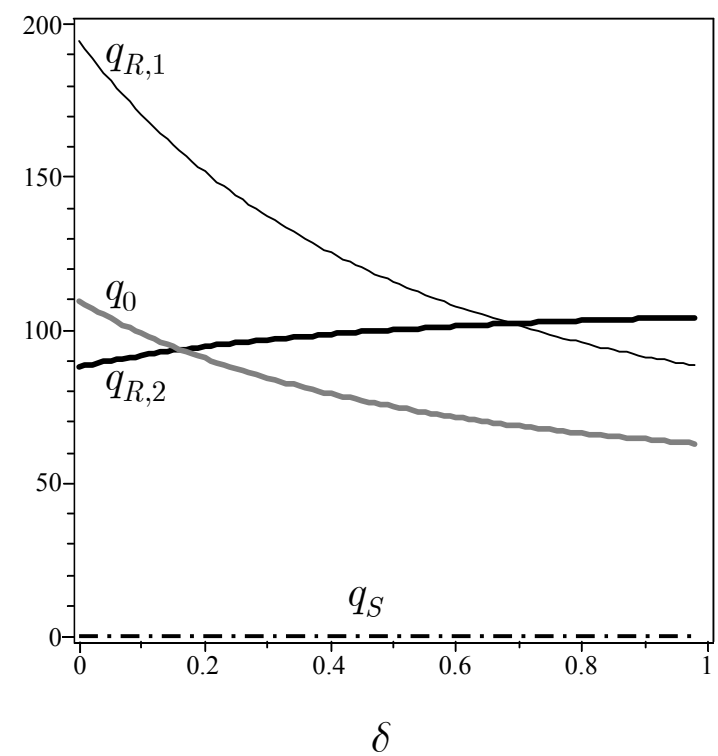

(b) Prices

(EUR / tcm)

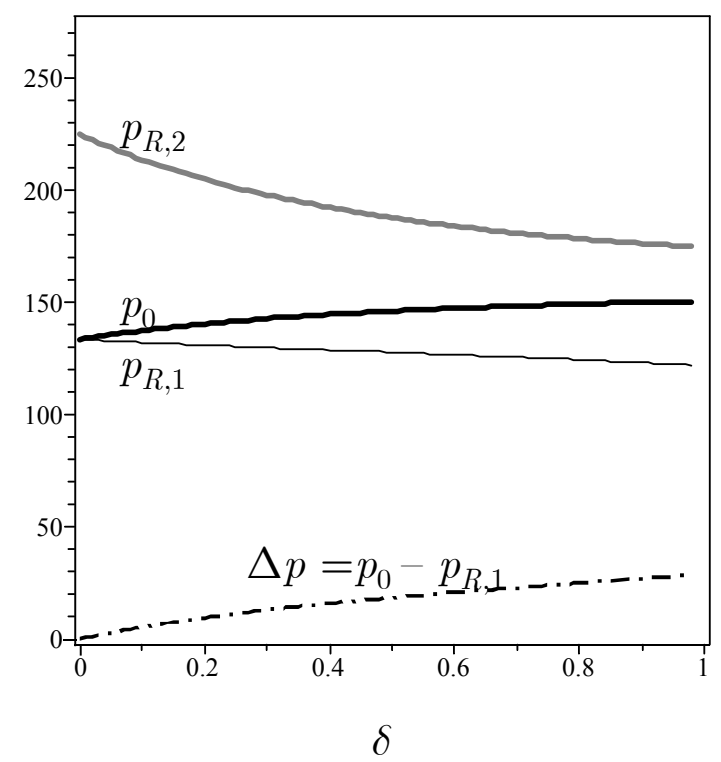


is held constant. The simulation results are shown in Figure 9 and are graphically similar to those in Figure 6, but the effects are more pronounced: Russia's monopolistic price $p_{R, 2}$ is obviously higher, its market share declines faster as a function of $\delta$, while its discount increases more steeply, as is expected based on equation (11). However, still no storage is built when $c_{S}=50$ EUR per tcm per year.

Secondly, let us double $k$ by increasing the long-run elasticity to twice its original value, while keeping $e_{S R}=-0.27 .{ }^{36}$ The results are shown in Figure 10. Because of the very high long-run elasticity, the volume of long-term gas import contracts with Russia for $\delta=0$ exceeds quite significantly the actual 2007 volume: $197 \mathrm{bcm}$ per year versus the actual 120 bcm per year. However, the large value of $k$ brings the volumes down quite rapidly as $\delta$ increases. As of $\delta \approx 0.5$ the results become graphically very similar to the base scenario in Figure 6.

All in all, the conclusions are fairly robust vis-à-vis changes in $k$.

\footnotetext{
${ }^{36}$ While this seems quite an extreme stress-test, one can argue that it is justified because long-run elasticity of domestic supply $q_{D}$ is ignored in this paper. Furthermore, note that a change in $\beta$ requires also a change in $\alpha$ to make sure that the new demand curve still passes through the same calibration point.
} 